\title{
COMPRENDERE LE BASI MOLECOLARI DELLA DISABILITÀ INTELLETTIVA ATTRAVERSO IL MODELLO DEI NEURONI DI CELLULE STAMINALI PLURIPOTENTI INDOTTE
}

\author{
Nota del s.c. LIDIA LARIZZA (*)
}

(Adunanza del 24 ottobre 2019)

SunTO. - Il punto di partenza di questa nota è il Premio Nobel per la Medicina assegnato nel 2012 all'inglese Sir John Gurdon e al giapponeses Shinya Yamanaka per la scoperta della "riprogrammazione cellulare", il processo per cui una cellula differenziata (matura) di un organismo può in determinate condizioni acquisire proprietà di cellula staminale pluripotente in grado di sviluppare tutte le cellule e i tessuti dell'organismo di provenienza. Oltre a rivoluzionare la nostra visione della biologia dello sviluppo tale scoperta ha permesso di generare in vitro cellule staminali pluripotenti (iPSC) da qualsiasi individuo, sano o malato e poi differenziarle come desiderato permettendo di modellare malattie che colpiscono tessuti e sistemi prima inaccessibili, come ad esempio il sistema nervoso ("brain in a dish"). In generale i modelli iPSC-derivati di malattie umane, genetiche o su base genetica, consentono di esplorarne i meccanismi patogenetici complementandosi ai modelli in vivo finora principalmente utilizzati (topo, ratto, zebrafish, drosophila) e costituiscono una piattaforma per lo screening di migliaia di piccole molecole o farmaci candidati per una data patologia selezionandoli in base alla capacità di far revertire alterazioni morfologiche, molecolari e funzionali registrate nelle cellule differenziate paziente-specifiche. Inoltre i modelli iPSC-derivati promettono potenzialità di terapia rigenerativa cellulo-mediata per malattie ad alta prevalenza benchè alcune problematiche quali i numeri di cellule necessarie e il loro corretto posizionamento nell'organo danneggiato rendano laboriosi gli sforzi in corso.

Abbiamo generato il primo modello neuronale iPSC-derivato per pazienti con Sindrome di Rubinstein-Taybi, un disordine mendeliano del neurosviluppo caratterizzato da dismorfismi facciali, ritardo della crescita e del linguaggio, displasia scheletrica,

(*) IRCCS Istituto Auxologico Italiano, Milano, Italy.

E-mail: 1.larizza@auxologico.it ; lidia.larizza@unimi.it 
malformazioni di vario tipo e deficit cognitivo spesso associato a disordine del comportamento. La sindrome risulta da mutazioni di uno dei geni omologhi CREBBP ed EP300 che codificano proteine che agiscono come "epigenetic writers" essendo coattivatori della trascrizione genica con attività acetiltransferasica diretta sia a istoni della cromatina che a proteine non istoniche. Benchè le mutazioni in questi geni siano irreversibili, le modificazioni epigenetiche determinate dal loro difetto sono reversibili aprendo potenziali opzioni terapeutiche postnatali volte ad attenuare il deficit cognitivo dei pazienti. Sono stati modellati sei pazienti RSTS, 4 CREBBP- e 2 EP300-mutati in parallelo a 4 individui sani: viene illustrato il work flow dalla riprogrammazione delle cellule mononucleate del sangue periferico alla generazione di iPSC, la loro caratterizzazione morfologica, immunoistochimica, citofluorimetrica, il loro potenziale a generare i tre foglietti embrionali e il differenziamento di linee iPSC validate per la stabilità genomica agli stadi di rosette neurali, progenitori neurali e neuroni corticali maturi. Benché i neuroni RSTS non presentino alla caratterizzazione immunoistochimica differenze evidenti nell' espressione di marcatori stadio-specifici rispetto a neuroni di controllo, l'analisi a due timepoints, ha rivelato biomarcatori distintivi. Allo stadio di neuroni in differenziamento (42 giorni), ancora a bassa densità in coltura e quindi passibili di analisi morfologiche precise, i neuroni di 4 su 5 pazienti RSTS presentano ridotta lunghezza e aumentato numero di "branches" (dendriti) rispetto a neuroni di controllo: la differenza è statisticamente significativa e l'unica eccezione è rappresentata dalla paziente con la disabilità intellettiva più lieve. Neuroni postmitotici (>70 giorni) RSTS caratterizzati con la tecnica di "voltage clamp" nostrano l'espressione di correnti di sodio e potassio analogamente ai controlli, e si dimostrano in grado di generare con la tecnica del "current clamp", seppur in percentuale inferiore al controllo, potenziali d'azione in risposta a stimoli depolarizzanti. Tuttavia i neuroni di tutti i pazienti risultano "ipoeccitabili" rispetto a neuroni di controllo, hanno cioè bisogno di uno stimolo di intensità superiore per raggiungere la soglia necessaria per generare potenziali d'azione.

In relazione all'identificazione nei neuroni RSTS di biomarcatori morfologici ed elettrofisiologici che li differenziano dai neuroni di individui sani, sono stati avviati esperimenti di trattamento dei neuroni del paziente RSTS con il fenotipo neurocognitivo più grave $(\mathrm{P} 149)$ con un inibitore delle istondeacetilasi, la tricostatina $\mathrm{A}$, dimostratosi in grado di migliorare il fenotipo neurologico in modelli murini $c b p+/-$. Risultati preliminari con TSA $20 \mathrm{nM}$ supplementata a due linee iPSC-.derivate di progenitori neurali di P149 hanno mostrato significativa, anche se parziale correzione di parametri morfologici alterati nei neuroni non trattati. Analogamente la somministrazione cronica per 5 settimane di TSA 0,2 nM alle colture di progenitori neurali di P149 ha mostrato significativo miglioramento delle proprietà elettrofisiologiche dei neuroni maturi $(>70$ giorni) di entrambe le linee di P149, ivi compresa la capacità di generare potenziali d'azione che non é significativamente diversa tra il controllo e il paziente trattato. La validazione di questi risultati mediante ulteriori sperimentazioni in vitro su neuroni di pazienti e controlli permetterà di integrare le modificazioni epigenetiche causate dal difetto di CBP/p300 nel contesto appropriato di omeostasi neuronale con un ulteriore passo in avanti verso trials clinici su pazienti RSTS in età pediatrica.

ABSTRACT. - In 2012 the Nobel Prize for Medicine was awarded to Sir John Gurdon and Shinya Yamanaka for their joined discovery that mature, specialized cells can be repro- 
grammed to become immature pluripotent cells capable of developing into all different tissues of the body. This seminal breakthrough changed our vision of developmental biology and made possible to generate in vitro from somatic cells of any healthy or affected individual Induced Pluripotent Stem Cells (iPSCs) and differentiate them into virtually all types of cells. Scientists around the world were provided with the tool of modelling human diseases, even those involving inaccessible tissues such as the nervous system, to study the pathological process. iPSCs also revealed an enormous potential for pharmaceutical and clinical applications as on these cells a myriad of small molecules or candidate drugs can be tested some of which hopefully will become new effective medicines for intractable diseases. We have generated the first iPSC-derived neuronal model for the Rubinstein-Taybi syndrome (RSTS), a mendelian neurodevelopmental disorder, characterized by facial dysmorphisms, growth and speech delay, skeletal dysplasia and intellectual disability often associated to behavior disorder. RSTS is caused by mutation in the homologous $C R E B B P$ and EP300 genes encoding proteins acting as chromatin regulators through their intertwined activity of transcriptional co-activators and acetyltransferases (KATs) on histone and non histone proteins. I summarize herein the workflow used to generate iPSC-derived neurons (iNeurons) from six RSTS patients with a variable cognitive impairment in parallel to iNeurons from four healthy controls. Immunohistochemical characterization of samples at the stages of iPSCs, neural rosettes, neural progenitors and post-mitotic cortical neurons did not reveal gross alterations in the expression of stagespecific differentiation markers across patients' or between patients' and controls' neuronal cultures. Conversely, altered morphology of patients' differentiating neurons, showing reduced branch length and increased branch number and hypoexcitability of differentiated neurons emerged as relevant "disease" biomarkers. Both the anomalous neuronal morphology and the impaired electrophysiological performance varied across iNeurons from different RSTS patients. possibly reflecting cognitive and behavioural impairment of the donor patients. To validate the identified morpho-functional markers we performed further studies on iNeurons from the RSTS patient with the most severe intellectual disability by using trichostatin A (TSA), an epidrug that by inhibiting histonedeacetylases (HDAcs), the KATs opposing enzymes, has been successfully applied in different $c b p+/ c b p$ - mouse models with improvement of some neurological abnormalities. Short acute and chronic TSA treatment of two independent neural progenitor lines from the selected RSTS patient determined in both replicas a consistent reversal of a few morphological abnormalities and a significant rescue of the defective electrophysiological performance, highlighting the potential postnatal intervention of epidrugs to ameliorate the cognitive impairment of RSTS patients.

\section{LA RIPROGRAMMAZIONE CELLULARE}

11 punto di partenza di questa nota è la scoperta della riprogrammazione cellulare, il fenomeno per cui cellule differenziate (mature) di qualsiasi tessuto di un organismo possono ritornare ad uno stadio indifferenziato immaturo "pluripotente" in grado di sviluppare tutti i tessuti di quell'organismo (Fig. 1). Questa scoperta ha rivoluzionato la 
nostra comprensione di come le cellule e gli organismi si sviluppano, ha avviato applicazioni importanti per la comprensione dell'eziologia di patologie genetiche e su base genetica e ha dischiuso ricadute terapeutiche.

Per questa scoperta nel 2012 il Premio Nobel per la Fisiologia e la Medicina è stato assegnato congiuntamente all'inglese Sir John Gurdon e al giapponese Shinya Yamanaka: Gurdon ha avuto l'intuizione geniale, che sfatava il dogma contemporaneo della biologia dello sviluppo, che il differenziamento cellulare non è irreversibile; Yamanaka più di 40 anni dopo ne ha fornito la dimostrazione sperimentale in un contesto scientifico notevolmente avanzato grazie alla ricerca sulle cellule staminali embrionali caratterizzate dall'inglese Martin Evans, Nobel per la Medicina nel 2007 (Fig. 2).

Nel dettaglio, nel 1962 John Gurdon scoprì che la specializzazione cellulare è reversibile: in un classico esperimento ha sostituito il nucleo di una cellula uovo di rana (Xenopus laevis), enucleata con radiazioni, con quello di una cellula dell'epitelio intestinale di rana. La cellula uovo così "modificata" si è sviluppata in un girino e quindi in una rana normale, dimostrando che il DNA della cellula matura dell'epitelio intestinale conserva tutta l'informazione necessaria a sviluppare tutte le cellule di quell'organismo (Gurdon, 1962). La scoperta seminale di Gurdon è stata inizialmente accolta con scetticismo, ma iniziò ad essere accettata perché le tecniche di "trasferimento nucleare" aprirono la strada alla clonazione dei mammiferi, a partire dalla pecora Dolly nel '97 da parte del gruppo dell'inglese Jan Wilnut, a quella di numerosi altri mammiferi, soprattutto bovini, fino ai primati. Dolly fu la prima clonazione riuscita di un mammifero adulto. Come tutti gli animali clonati Dolly è nata in provetta dal trasferimento del nucleo di una cellula di ghiandola mammaria di pecora nella cellula uovo enucleata di un'altra pecora: una volta che il normale sviluppo è stato confermato, l'embrione, che alla fine sarebbe diventato Dolly, è stato trasferito in una madre surrogata. Tecnicamente quindi Dolly ha avuto tre madri!

Nonostante l'estesa ricaduta scientifica e biotecnologica degli esperimenti di Gurdon rimanevano ancora riserve sulle manipolazioni con pipette per la rimozione del nucleo e la sua introduzione in altre cellule: sarebbe mai stato possibile riprogrammare una cellula "intatta" in una cellula staminale pluripotente? 
Nel 2006 Shinia Yamanaka è stato in grado di dare una risposta a questa domanda nel contesto della sua ricerca focalizzata sulle cellule staminali pluripotenti isolate dall'embrione e coltivate in laboratorio. Tali cellule erano state inizialmente caratterizzate da M. Evans e il gruppo di Yamanaka cercava di identificare i geni in grado di mantenerle nello stato di pluripotenza. A seguito dell'identificazione di parecchi di tali geni testava quale fosse in grado di riprogrammare cellule mature a cellule staminali pluripotenti. Introducendo diverse combinazioni geniche in cellule mature del tessuto connettivo di topo (fibroblasti) e analizzando i risultati al microscopio, trovò alla fine una combinazione di soli quattro geni (OCT4, SOX2, KLF4 e c-MYC ) che induceva la riprogrammazione dei fibroblasti a cellule staminali. Le cellule staminali pluripotenti indotte (iPSC) erano poi in grado di differenziarsi in tutti i tipi di cellule mature del topo, dai fibroblasti ai neuroni alle cellule dell'epitelio intestinale (Takahashi E Yamanaka, 2006). La dimostrazione l'anno succesivo che cellule mature "intatte" possono essere riprogrammate per i fibroblasti umani (Takahashi et al., 2007) è stata immediatamente recepita come scoperta con grandi potenzialità nella medicina clinica.

Le scoperte di Gurdon e Yamanaka hanno profondamente modificato i concetti cardine della biologia dello sviluppo quali il differenziamento terminale considerato processo "irreversibile". Le iPSC sono simili alle cellule staminali embrionali (derivanti da embrioni allo stadio di blastocisti) nella morfologia, proliferazione, antigeni di superficie e geni di pluripotenza. Come le cellule staminali embrionali sono in grado di differenziarsi nei tipi cellulari dei tre foglietti (ecto, meso e endodermico) in vitro e di generare teratomi in vivo. Hanno però il grande vantaggio di non creare tutti i problemi etico-legali delle cellule staminali embrionali per la loro derivazione da qualsiasi tipo di cellule somatiche di individui sani e malati.

\section{MODELLI IN VITRO DI MALATTIE UMANE}

Riprogrammando cellule umane gli scienziati hanno creato nuove opportunità per studiare malattie generando modelli in vitro malattiae paziente-specifici a partire da vari tipi di cellule "periferiche" (sangue, cute, urina, etc ). Ciò si è rivelato particolarmente utile per disordini di 
sistemi ed organi difficilmente accessibili quali ad esempio il Sistema Nervoso Centrale, per il quale il tessuto umano fonte della maggior parte della sperimentazione é stato il cervello "post mortem" che, a parte le problematiche di accessibilità, etiche e politiche, non permette lo studio del periodo fetale dello sviluppo cerebrale, mentre è noto che la maggior parte della formazione del cervello umano avviene in epoca prenatale. Naturalmente modelli animali hanno supplito a tale carenza, ma solo parzialmente per le differente organizzazione del cervello nel topo e nell'uomo.

Modellare malattie umane in vitro ha permesso di decodificarne i meccanismi eziopatogenetici: nel caso dei disordini del neurosviluppo (Zhao \& Bhattacharyya, 2018) in cui rientra la sindrome di RubinsteinTaybi che tratterò a breve, e di malattie neurodegenerative il confronto dei neuroni in vitro di pazienti e individui sani a tempi diversi di differenziamento ha evidenziato "biomarcatori" morfologici, elettrofisiologici e molecolari utilizzabili per la terapia. I modelli in vitro di cellule differenziate da iPSC offrono infatti la piattaforma per test ad alta processività di migliaia di prodotti naturali e chimici o per lo screening di farmaci già noti come candidati per una data patologia: sia nel primo che nel secondo caso le alterazioni delle cellule paziente-specifiche devono revertire dopo l'esposizione al farmaco in vitro per portare a studi preclinici in vivo su modelli animali e trials clinici su pazienti (Avior et al., 2016)(Fig. 3).

Le iPSC hanno alimentato grandi speranze anche nel campo della medicina rigenerativa: la possibilità di indurre il differenziamento nella maggior parte dei tipi cellulari di un organismo (neuroni, cellule pancreatiche, cardiache, epatiche etc ) può essere infatti sfruttata nella rigenerazione/riparazione di tessuti o organi danneggiati (terapia rigenerativa cellulo-mediata). Tuttavia, benché molti sforzi siano stati fatti e siano tuttora in corso per malattie ad alta prevalenza, quali ad esempio la maculopatia degenerativa dovuta all'età, il Parkinson, il diabete, le lesioni traumatiche del midollo spinale, i costi dovuti al numero astronomico di cellule da differenziare in vitro paziente-specifiche, che come tali quindi non creerebbero alcun rigetto immunitario, ma potrebbero acquisire mutazioni nel corso del lungo periodo di coltura e soprattutto il posizionamento corretto nell'organo danneggiato, non hanno portato finora a risultati incoraggianti, nonostante trials clinici di fase 1 e 2 siano in corso per le patologie sopramenzionate (Trounson E DeWitt, 2016). 
GENERAZIONE DEL MODELLO NEURONALE PER LA SINDROME CON DISABILITÀ INTELLETTIVA RUBINSTEIN-TAYBI

Abbiamo generato il modello iPSC neuronale per una sindrome genetica a trasmissione autosomico dominante, la sindrome di Rubinstein-Taybi (RSTS), caratterizzata da ritardo di crescita e psicomotorio, dismorfismi facciali, displasia scheletrica e disabilità intellettiva, definita come difetto di funzioni cognitive e di comportamento che si verifica durante lo sviluppo (Fig. 4) (Hennekam, 2006; Larizza E Finelli, 2019). L'incidenza é 1:125.000 nati, ma sale a 1:300 in pazienti istituzionalizzati con ritardo mentale. RSTS è causata da mutazioni o nel gene CREBBP o nel suo omologo EP300 (Spena et al., 2015; Negri et al., 2016) che codificano le proteine multifunzionali CBP e p300, coattivatori della trascrizione genica con attività $\mathrm{K}$ (lisina) acetiltransferasica (KAT) diretta agli istoni della cromatina e a proteine nucleari non istoniche (Figg. 5, 6, 7) (Sheikh e Akbtar, 2019). La cromatina è il complesso del DNA che si avvolge attorno a ottameri di istoni: la sequenza delle basi del DNA attraverso il codice genetico detta l'informazione genetica che è stabile e irreversibile, mentre modificazioni dei gruppi metilici della citosina (una delle quattro basi del DNA), modificazioni post-traduzionali degli istoni, quali acetilazione, metilazione etc. e modificazioni opposte (deacetilazione, demetilazione etc), varianti istoniche e piccoli RNA non codificanti costituiscono l'informazione epigenetica, che è dinamica e reversibile (Figg. 8 e 9). Le modificazioni epigenetiche regolano la struttura tridimensionale della cromatina rendendola più o meno adatta alla trascrizione genica e sono quindi alla base dei programmi genetici tessuto-specifici. Le proteine CBP e p300 introducendo il gruppo acetilico donato dall'acetilcoenzima A nelle code di lisina di istoni e fattori di trascrizione agiscono come "epigenetic writers": il marchio epigenetico viene rimosso da enzimi con attività opposta, le iston-deacetilasi che sono "epigenetic erasers". Esiste una bilancia tra acetilazione e deacetilazione che è molto importante, specie per l'omeostasi neuronale: pertanto mutazioni di CREBBP o EP300 e difetto di CBP o p300 spostano l'equilibrio a favore della deacetilazione e uno stato di cromatina "chiusa" non compatibile alla trascrizione. RSTS è una cromatinopatia: patologia in cui è difettoso per mutazione il gene per una 
proteina componente dell'apparato epigenetico della cellula. I principali attori della macchina epigenetica sono oltre ai "writers" e gli "erasers" i "readers", proteine in grado di leggere il marchio epigenetico e i "remodellers", enzimi che usano l'energia dell'ATP per rimodellare la cromatina favorendo interazioni DNA-proteine (Fig. 10). Il gruppo dei disordini dell'apparato epigenetico, definito nel 2015 (Bijornsson, 2015) e in progressiva espansione (Fabrner et al., 2019) comprende sindromi mendeliane che condividono disabilità intellettiva e difetti della crescita (Fig. 11) sulle quali si è concentrata l'attenzione per la potenziale applicazione postnatale di terapie dirette all' attenuazione del deficit cognitivo. Difatti, benché la mutazione di un gene "epigenetico" sia irreversibile, i cambiamenti epigenetici che ne conseguono possono essere contrastati adottando farmaci che ripristinino lo stato di equilibrio alterato.

$\mathrm{Al}$ fine di acquisire una migliore comprensione dei meccanismi alla base del deficit cognitivo di pazienti RSTS abbiamo generato in vitro un modello di neuroni iPSC-derivati riprogrammando cellule del sangue periferico di 6 pazienti RSTS, 4 CREBBP- e 2 EP300-mutati manifestanti un diverso grado disabilità intellettiva associato in tre a disordine del comportamento: in parallelo sono state riprogrammate cellule del sangue periferico di 4 individui sani (Fig. 12). Il workflow della riprogrammazione e del differenziamento neuronale è dettagliato in Fig. 13.

\section{DALLE IPSC PAZIENTE-SPECIFICHE AI NEURONI: CARATTERIZZAZIONE IMMUNOISTOCHIMICA}

Come mostrato nel workflow (Fig. 13) le iPSC sono generate dalle cellule mononucleate del sangue periferico di pazienti RSTS e individui sani utilizzando dopo 9 giorni di arricchimento delle cellule da riprogrammare (eritroblasti) il metodo del virus Sendai $(\mathrm{SeV})$ raccomandato perché non integrativo (il virus non si integra nel genoma delle cellule riprogrammate dalle quali progressivamente scompare). Particelle di SeV trasducono nelle cellule bersaglio RNA per i 4 fattori di Yamanaka; le cellule trasdotte sono quindi piastrate su fibroblasti embrionali di topo (MEFs) irradiati in terreno per cellule staminali 
embrionali. A partire dal 20 giorno le colonie emergenti sono prelevate e trasferite in nuove piastre con "feeder layer" per essere poi testate per la morfologia, l'espressione qualitativa (mediante immunofluorescenza) e quantitativa (mediante citofluorimetria) degli antigeni di staminalità (OCT4, SSEA4, TRA-1-60) e la capacità di differenziarsi nei tre foglietti dell'embrione, ectoderma, mesoderma e endoderma (Fig. 14). Le colonie iPSC (almeno 3 per ciascun donatore) sono caratterizzate mediante analisi del cariotipo, ibridazione genomica comparativa su array $(\mathrm{aCGH})$ e sequenziamento Sanger del DNA (Fig. 15). I cloni iPSC che superano il controllo della stabilità genomica usando come riferimento le cellule somatiche (sangue periferico) del donatore sono poi differenziati in neuroni corticali secondo il protocollo in monostrato che utilizza "Neurobasal Medium" supplementato con noggina. Dopo circa due settimane il differenziamento neurale è marcato dalla comparsa delle tipiche "rosette" che sono molto simili a sezioni trasversali del tubo neurale durante lo sviluppo del sistema nervoso in vivo (Fig. 16). Allo stadio di rosette la maggior parte delle cellule di pazienti RSTS così come di individui sani mostra positività all'immunofluorescenza per i marcatori neuroectodermici Nestina e PAX6 (Fig. 17), confermata dal rilievo degli stessi marcatori mediante analisi di espressione con RT-PCR (Reverse Transcription PCR ). Con taglio manuale e trasferimento in nuove piastre le rosette sono poi indotte a differenziarsi in Progenitori Neurali (NPCs) (35esimo giorno) mediante sostituzione al 28esimo giorno del terreno di base con "Neural Differentiation Medium". I progenitori neurali proliferano e sono ulteriormente indotti al differenziamento terminale, per cui solo aliquote di NPCs al 35 giorno sono stoccabili in azoto liquido e riscongelabili per futuri esperimenti. A 42 giorni i neuroni sia di controlli che di pazienti esprimono i marcatori panneuronali MAP2 (microtubule-associated protein 2) e TUJ1 (betaIII-tubulin) (Fig. 18). Sui neuroni a questo stadio è effettuata l'analisi morfologica (vedi oltre). Dopo prolungato mantenimento in coltura ( $>70$ giorni) $\mathrm{i}$ neuroni di pazienti RSTS sviluppano come quelli di controlli una intricata rete di cellule arricchita in neuroni corticali, positivi per l'espressione di TBR-1, regolatore master dello sviluppo corticale, CUX1 necessario per la formazione dei dendriti (Fig. 19), e il marcatore pre-sinaptico sinaptofisina (SYP) (Fig. 20). La maggior parte dei neu- 
roni maturi di pazienti RSTS come di controlli sono positivi per il marcatore glutamatergico vGLUT (Fig. 21), tipico dei neuroni eccitatori, mentre pochi lo sono per il marker dei neuroni inibitori GAD65/67 (Fig. 21). Sotto il profilo qualitativo non sono evidenti differenze significative nel differenziamento in vitro di neuroni RSTSspecifici rispetto a neuroni di controllo. Sui neuroni posmitotici $(>70$ giorni) è effettuata l'analisi elettrofisiologica (vedi oltre) e saggi molecolari che possono comprendere l'analisi dell'intero trascrittoma.

\section{ANALISI DELLA MORFOLOGIA DI NEURONI (42 GIORNI) DI RSTS E CONTROLLI}

Ci siamo avvalsi dello stadio di neuroni giovani (42-45 giorni) ancora in coltura a bassa densità per stabilire se alcune caratteristiche morfologiche, quali la lunghezza e il numero di dendriti o "branches" differiscono tra neuroni RSTS e di controlli. A tal fine abbiamo utilizzando la Plugin "Analyse Skeleton" che permette di elaborare la cellula la cui identità neuronale è accertata dalla positività in immunofluorescenza per MAP2 e TUJ1(Fig. 22) in un'immagine binaria e di ottenerne lo "skeleton" per poter stimare precisamente il numero e la lunghezza dei branches in un campione di neuroni di pazienti e controlli. L'analisi di un numero di 30-50 cellule di vetrini trattati con gli anticorpi specifici di 3 controlli e 5 pazienti ha messo in luce in 4 su 5 pazienti una lunghezza media dei branches significativamente ridotta ed un numero medio dei branches significativamente aumentato rispetto ai controlli (Fig. 23): il paziente che non si diversifica dai controlli è quello con disabilità intellettiva più lieve (P46) portatore di una mutazione missenso di CREBBP che porta a sostituzione di un residuo aminoacidico nel dominio KAT causando attività acetiltrasferasica defettiva, ma non aploinsufficienza, come confermato dal Western Blot su estratti di iPSC di P46 che rileva con un anticorpo per la porzione-N-terminale di CBP una proteina "full length" in quantità analoga ai controlli (Alari et al., 2019). L'analisi di correlazione tra i due parametri morfologici valutati nei neuroni di pazienti e controlli conferma la tendenza opposta nei pazienti RSTS, mentre la correlazione è debole nei controlli (Fig. 23). 


\section{ELETTROFISIOLOGIA DEI NEURONI CORTICALI MATURI}

Neuroni maturi ( $>70$ giorni) di un controllo e 4 pazienti RSTS sono stati analizzati mediante "patch-clamp recordings" per testare la loro maturità ed eccitabilità. Gli esperimenti hanno mostrato che i neuroni dei pazienti esprimono correnti di sodio e di potassio analogamente a neuroni maturi normali, come evidenziato dalle tracce rappresentative di un controllo e 4 pazienti (Fig. 24, primo pannello). Anche le correnti di potassio presentano ampiezze simili nei pazienti 46, 207 e 65, mentre risultano lievemente ma significativamente aumentate in P34 (Fig. 24 secondo pannello). Esperimenti relativi al "clamp" delle correnti hanno confermato che i neuroni dei pazienti sono in grado di generare potenziali di azione in risposta a stimoli depolarizzanti, benché quelli di P34 e P207 in percentuale minore (Fig. 24, terzo pannello). Inoltre i neuroni di tutti i pazienti analizzati sono risultati "ipoeccitabili" rispetto a quelli dei controlli, come mostrato dai rapporti input-output (Fig. 24 quarto pannello).

Le conclusioni di questo studio sono illustrate nella Fig. 25 che schematizza i risultati raggiunti, ovvero: la generazione e caratterizzazione di un modello neuronale iPSC-derivato per la sindrome RSTS, sia causata da mutazioni di CREBBP, che di EP300 e l' identificazione di biomarcatori che distinguono i neuroni dei pazienti da quelli di individui sani consistenti in alterazioni morfologiche (numero e lunghezza dei dendriti) dei neuroni giovani e alterazioni elettrofisiologiche indicative di una più lenta risposta agli stimoli (ipoeccitabilità) dei neuroni maturi. Maggiori dettagli del percorso sperimentale e degli approcci metodologici impiegati sono contenuti in Alari et al., 2018a, Alari et al., $2018 b$ e Alari et al., 2019.

TRATTAMENTO DEI NEURONI DI PAZIENTI RSTS IN VITRO CON POTENZIALI AGENTI TERAPEUTICI

E' stato sottolineato che la sindrome RSTS è annoverata tra i disordini dell'apparato epigenetico per i quali è possibile una terapia postnatale che porti ad attenuazione della disabilità intellettiva. La disponibilità del modello neuronale in vitro permette di utilizzare pic- 
cole molecole candidate a contrastare il difetto derivante dal deficit di acetilazione che sono gli inibitori delle iston-deacetilasi (HDACi) (Fig. 26). Esiste un'ampia gamma di tali composti molti dei quali utilizzati con successo nella cura di diverse patologie genetiche, su base genetica e tumorali (Ganai, 2016): tra questi i derivati degli acidi idrossamici SAHA/Vorinostat e tricostatina A (TSA) sono stata già testati in vivo in diversi modelli di topo $c b p+/ c b p$ - con miglioramento di vari difetti neurologici (Alarcon et al., 2004; Korzus, 2004), e dal nostro gruppo in vitro su linee linfoblastoidi di pazienti CREBBP-mutati in cui hanno determinato incremento del livello di acetilazione degli istoni della cromatina (Lopez-Atalaya J, 2012).

Abbiamo selezionato tra i pazienti RSTS modellati in vitro P149, che presenta il fenotipo neurologico più grave, sulla base anche di malformazioni cerebrali (ipoplasia del corpo calloso e ipoplasia cerebellare) e il più accentuato deficit cognitivo (Fig. 12) per effettuare esperimenti con tricostatina A (TSA) e valutare una possibile reversione delle alterazioni morfologiche ed elettrofisiologiche documentate nei neuroni giovani (45 giorni) e maturi ( $>70$ giorni) dei pazienti RSTS. Per il primo timepoint (trattamento acuto) la supplementazione del terreno di coltura ha utilizzato per una settimana TSA 20nM, dose indicata da saggi di tossicità come la più alta che non influenza la percentuale di cellule vive sia nelle linee di controllo che nelle linee del paziente. Per il trattamento cronico (almeno 5 settimane) si è impiegata TSA $0,2 \mathrm{nM}$.

Risultati preliminari su neuroni differenziati dai progenitori derivati da due cloni iPSC (6 e 7) di P149 mostrano rispetto a quelli ottenuti dai progenitori di controlli ridotta dimensione dei nuclei (Fig. 27) e diminuita lunghezza media dei branches (dendriti): questi parametri morfologici sono parzialmente, ma significativamente corretti dal trattamento con TSA.

11 trattamento a lungo termine (5 settimane) dei progenitori neurali di un controllo e di P149 con TSA 0,2nM fino allo stadio di neuroni maturi ( $>75$ giorni) ha analogamente mostrato miglioramento dei parametri elettrofisiologici rispetto ai neuroni del paziente non trattati: quantificando la percentuale di neuroni in grado di generare almeno un potenziale d'azione con stimoli depolarizzanti si osserva differenza significativa tra il controllo e P149 non trattato così come tra P149 non 
trattato e trattato con TSA, mentre non c' è differenza significativa tra controllo e P149 trattato con TSA (Fig. 28).

Questi risultati, i primi ad essere ottenuti su "neuroni" di pazienti RSTS, necessitano di convalida con esperimenti complementari di analisi citofluorimetrica dei marcatori di maturità neuronale del paziente 149 rispetto al controllo ai due time points indagati. Benché preliminari, essi tuttavia suggeriscono potenziali benefici di terapie postnatali per pazienti con questo disordine epigenetico, essendo dimostrata nel modello murino la rilevanza del deficit di CBP non solo durante lo sviluppo del cervello ma anche per le attività cognitive nel corso della vita (Korzus , 2004). L'adozione della terapia con "epidrugs" per i pazienti RSTS necessita inoltre ottimizzazioni relative alla specificità di substrato dei diversi tipi di HDACi e alla loro tossicità in trattamenti cronici. Pur con queste riserve tuttavia solo sperimentazioni in vitro sulle cellule neuronali di pazienti e controlli potranno integrare le modifiche di acetilazione degli istoni e proteine non istoniche causate dal difetto di $\mathrm{CBP} / \mathrm{p} 300$ nel contesto appropriato di omeostasi neuronale.

\section{RINGRAZIAMENTI}

Si ringraziano i pazienti e le loro famiglie per la partecipazione a questo studio e l'Associazione Italiana per la Sindrome di Rubinstein-Taybi "Una Vita Speciale". Il lavoro di ricerca è stato supportato dal progetto ERA-NET NEURON JTC2015 ChromiSyn.

\section{BIBLIOGRAFIA}

Gurdon, JB. The developmental capacity of nuclei taken from intestinal epithelial cells of feeding tadpoles. J Embryol Exp Morph 10, 622-640, 1962.

Takahashi, K. \& Yamanaka, S. Induction of pluripotent stem cells from mouse embryonic and adult fibroblast cultures by defined factors. Cell 126, 663-676, 2006.

Takahashi, K. et al. Induction of pluripotent stem cells from adult human fibroblasts by defined factors. Cell 131, 861-872, 2007.

Zhao X. \& Bhattacharyya A. Human Models Are Needed for Studying Human Neurodevelopmental Disorders. Am J Hum Genet 103, 829-857, 6, 2018.

Avior Y et al . Pluripotent stem cells in disease modelling and drug discovery. Nat Rev Mol Cell Biol. 17(3):170-182, 2016 doi:10.1038/nrm.2015.27 
Trounson A \& DeWitt ND. Pluripotent stem cells progressing to the clinic. Nat Rev Mol Cell Biol. 17(3):194-200, 2016. doi:10.1038/nrm.2016.10

Hennekam, R.C. Rubinstein-Taybi syndrome. Eur. J. Hum. Genet. 14(9), 981-985, 2006. doi: 10.1038/sj.ejhg.5201594.

Larizza L, Finelli P. Developmental disorders with intellectual disability driven by chromatin dysregulation: Clinical overlaps and molecular mechanisms. Clin Genet. 95(2):231-240., 2019 doi: 10.1111/cge.13365

Spena, S., Milani, D., Rusconi, D., Negri, G., Colapietro, P., Elcioglu, N., et al. Insights into genotype-phenotype correlations from CREBBP point mutation screening in a cohort of 46 Rubinstein-Taybi syndrome patients. Clin. Genet. 88(5), 431440., 2015 doi: 10.1111/cge.12537.

Negri, G., Magini, P., Milani, D., Colapietro, P., Rusconi, D., Scarano, E., , Bonati MT, Priolo M, Crippa M, Mazzanti L, Wischmeijer A, Tamburrino F, Pippucci T, Finelli P, Larizza L, Gervasini C. From Whole Gene Deletion to Point Mutations of EP300-Positive Rubinstein-Taybi Patients: New Insights into the Mutational Spectrum and Peculiar Clinical Hallmarks. Hum. Mutat. 37(2), 175183, 2016 doi: 10.1002/humu.22922.

Sheikh, B.N., and Akhtar, A.. The many lives of KATs - detectors, integrators and modulators of the cellular environment. Nat. Rev. Genet. 20(1), 7-23, 2019. doi: 10.1038/s41576-018-0072-4.

Bjornsson, H.T.. The Mendelian disorders of the epigenetic machinery. Genome Res. 25(10), 1473-1481, 2015 doi: 10.1101/gr.190629.115.

Fahrner, J. A., \& Bjornsson, H. T. Mendelian disorders of the epigenetic machinery: postnatal malleability and therapeutic prospects. Human Molecular Genetics, 28(R2), R254-R264, 2019 doi:10.1093/hmg/ddz174

Alari V, Russo S, Rovina D, Garzo M, Crippa M, Calzari L, Scalera C, Concolino D, Castiglioni E, Giardino D, Prosperi E, Finelli P, Gervasini C, Gowran A, Larizza L Generation of three iPSC lines (IAIi002, IAIi004, IAIi003) from RubinsteinTaybi syndrome 1 patients carrying CREBBP non sense c.4435G $>$ T, p.(Gly1479*) andc.3474G $>$ A, p. $\left(\operatorname{Trp} 1158^{*}\right)$ and missense c.4627G $>$ T, p.(Asp1543Tyr) mutations. Stem Cell Res.;40:101553., 2019. doi: 10.1016/ j.scr.2019.101553.

Alari V, Russo S, Terragni B, Ajmone PF, Sironi A, Catusi I, Calzari L, Concolino D, Marotta R, Milani D, Giardino D, Mantegazza M, Gervasini C, Finelli P, Larizza L. iPSC-derived neurons of CREBBP- and EP300-mutated Rubinstein-Taybi syndrome patients show morphological alterations and hypoexcitability. Stem Cell Res. 30:130-140, 2018. doi: 10.1016/j.scr.2018.05.019.

Alari V, Russo S, Rovina D, Gowran A, Garzo M, Crippa M, Mazzanti L, Scalera C, Prosperi E, Giardino D, Gervasini C, Finelli P, Pompilio G, Larizza L. Generation of the Rubinstein-Taybi syndrome type 2 patient-derived induced pluripotent stem cell line (IAIi001-A) carrying the EP300 exon 23 stop mutation c.3829A > T, p.(Lys1277*). Stem Cell Res. 30:175-179, 2018 doi: 10.1016/ j.scr.2018.06.009.

Ganai SA, Ramadoss M, Mahadevan V. Histone Deacetylase (HDAC) Inhibitors emerging roles in neuronal memory, learning, synaptic plasticity and neural rege- 
neration. Curr Neuropharmacol.14(1):55-71, 2016 doi:10.2174/1570159x 13666151021111609

Alarcón JM, Malleret G, Touzani K, et al. Chromatin acetylation, memory, and LTP are impaired in $\mathrm{CBP}+/$ - mice: a model for the cognitive deficit in Rubinstein-Taybi syndrome and its amelioration. Neuron. 42(6):947-959., 2004 doi:10.1016/j.neuron.2004.05.021

Korzus E, Rosenfeld MG, Mayford M. CBP histone acetyltransferase activity is a critical component of memory consolidation. Neuron.42(6):961-972, 2004. doi:10.1016/j.neuron.2004.06.002

Lopez-Atalaya, J.P., Gervasini, C., Mottadelli, F., Spena, S., Piccione, M., Scarano, G., Selicorni A, Barco A, Larizza L.. Histone acetylation deficits in lymphoblastoid cell lines from patients with Rubinstein-Taybi syndrome. J. Med. Genet. 49(1), 66-74, 2012 doi: 10.1136/jmedgenet-2011-100354. 


\section{RIPROGRAMMAZIONE CELLULARE}

\section{CELLULE DIFFERENZIATE}

(sangue, cute, pancreas, fegato, muscolo...)<smiles>[Te]</smiles>

CELLULE STAMINALI PLURIPOTENTI INDOTTE in grado di sviluppare tutti $i$ tessuti di un organismo iPSCs

Applicazioni:

Comprensione biologia dello sviluppo

Modelli cellulari in vitro per esplorare meccanismi alla base di patologie

Applicazioni terapeutiche paziente-specifiche

Terapia rigenerativa cellulo-mediata
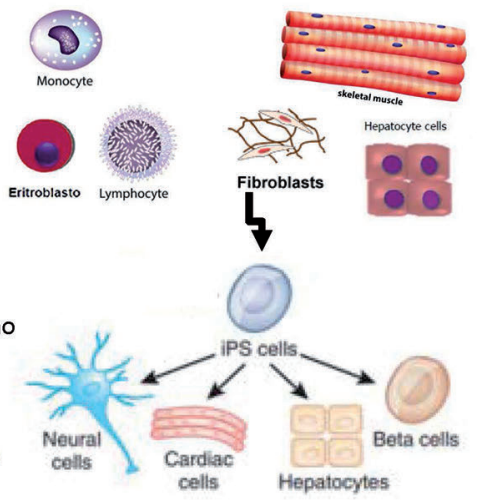

ells

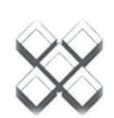

Fig. 1. Schema e applicazioni della riprogrammazione cellulare, il processo per cui cellule differenziate mature possono essere "indotte" a diventare cellule staminali pluripotenti (iPSC) in grado di differenziarsi in tutti i tessuti dell'organismo. 


\section{Nobel per la Medicina 2012}

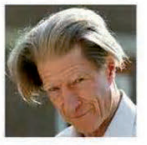

John B. Gurdon
Wh

(1)

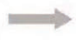

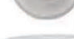
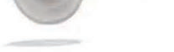
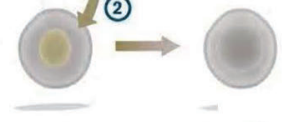

(3)

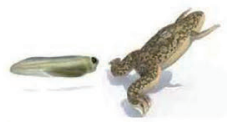

(4)

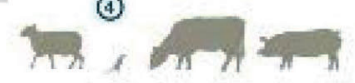

(1)
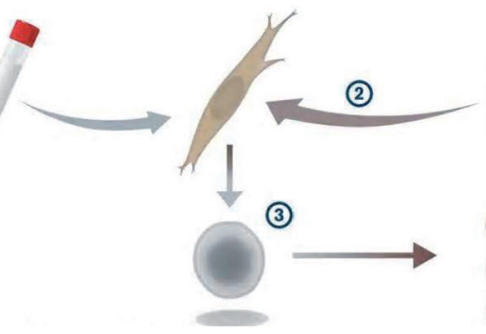

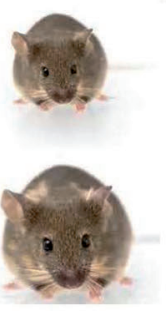

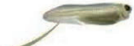

(2)

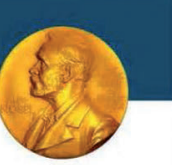

\section{$8 \geq$}

Fig. 2. Il Nobel per la medicina del 2012 condiviso dall'inglese Sir John Gurdon e dal giapponese Shynia Yamanaka. Gli esperimenti di Gurdon di "trasferimento nucleare" (1962) dimostrano che il nucleo di una cellula differenziata dell'epitelio intestinale di rana trasferito nella cellula uovo enucleata di rana può generare una cellula pluripotente da cui si sviluppa l'intero organismo della rana. Questi esperimenti hanno aperto la strada alla clonazione dei mammiferi, dalla pecora Dolly ai primati, ma sono stati accolti con riserve per via delle manipolazioni necessarie per indurre la riprogrammazione cellulare. Più di 40 anni dopo il gruppo di Yamanaka dimostra che una cellula differenziata del tessuto connettivo del topo (fibroblasto) "intatta" può essere riprogrammata in provetta a cellula pluripotente con una combinazione di soli 4 geni (identificati tra quelli in grado di mantenere lo stato di pluripotenza di cellule staminali embrionali) ed è poi in grado di generare l'intero organismo del topo. 


\section{iPSC MODEL}
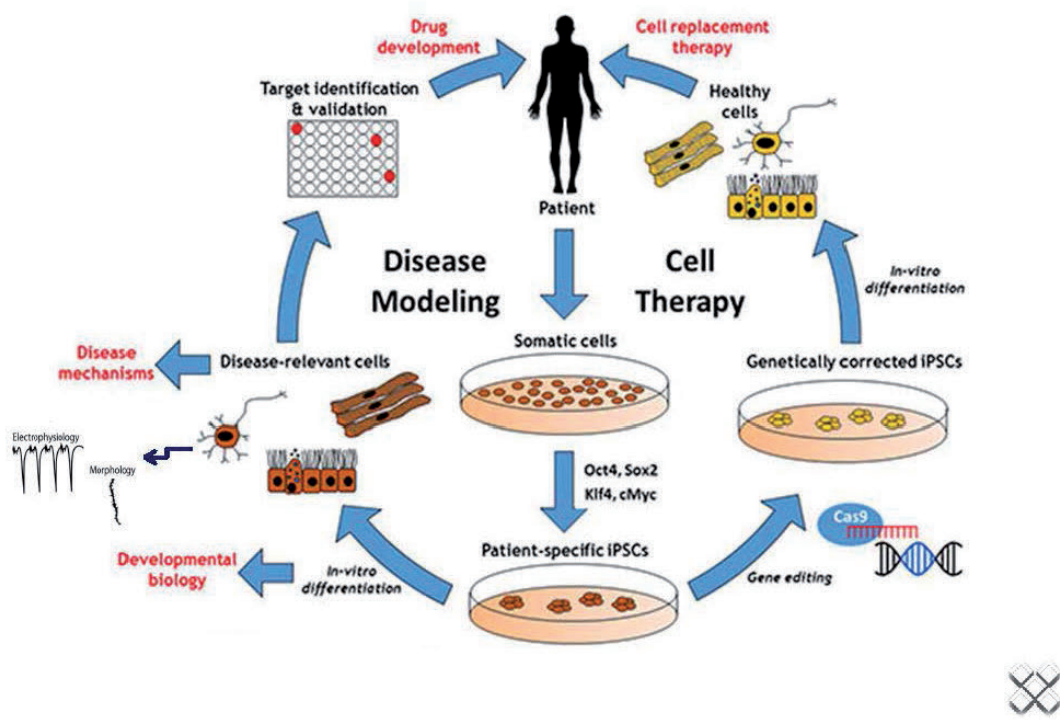

Fig. 3. Il modello dello cellule staminali pluripotenti indotte (iPSC): da cellule somatiche di un paziente con una patologia di interesse si generano tramite riprogrammazione con $i$ fattori di Yamanaka iPSC che vengono fatte differenziare in vitro come desiderato (pannello a sinistra). Nel caso di differenziamento a neuroni si effettuano vari saggi, quali l'analisi morfologica e l'elettrofisiologia per caratterizzarli rispetto a neuroni ottenuti da individui sani. Si possono anche testare piccole molecole (farmaci) per valutare la possibile reversione al fenotipo di neuroni normali. Dalle iPSC (pannello a destra) è possibile con tecniche di "editing" correggere le mutazioni paziente-specifiche e ottenere cellule differenziate normali da utilizzare per terapia sostitutiva paziente-specifica. 


\section{RUBINSTEIN TAYBI RSTS1: MIM\#180849 RSTS2: MIM\#613684}
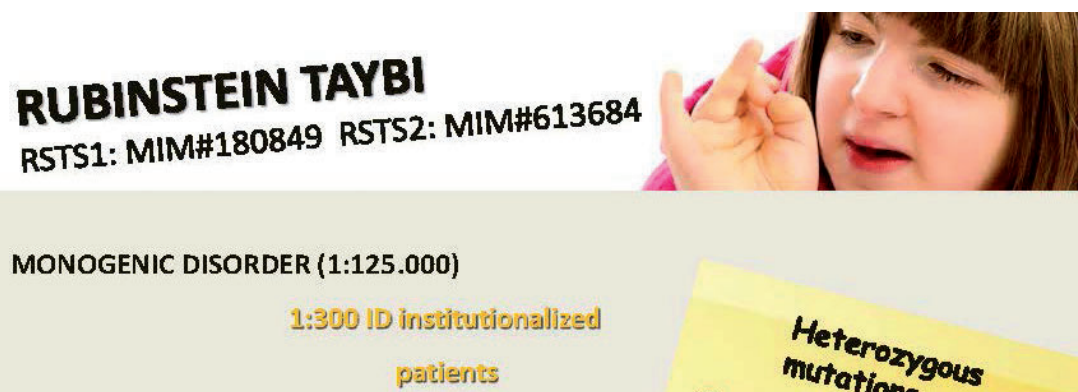

Fig. 4. La sindrome di Rubinstein-Taybi (RSTS): patologia Mendeliana rara a trasmissione autosomico dominante, comprendente due entità cliniche, RSTS1 e RSTS2, causate da mutazioni nei geni omologhi CREBBP ed EP300. Sono elencati i principali segni clinici: tra questi la disabilità intellettiva, presente in tutti (RSTS1) o quasi tutti (RSTS2) i pazienti. I meccanismi alla base del deficit cognitivo dei pazienti RSTS possono essere studiati attraverso il modello di iPSC paziente-specifiche differenziate in vitro a neuroni corticali. 


\section{RSTS GENES}

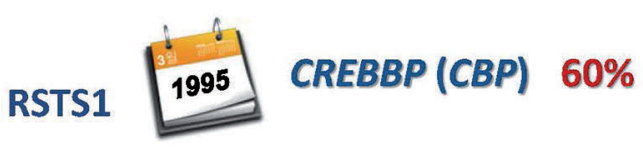

CREB (cAMP-response element binding protein) Binding Protein

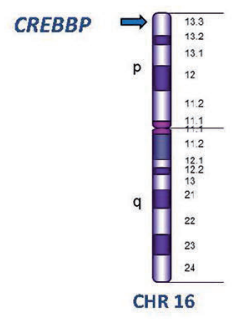

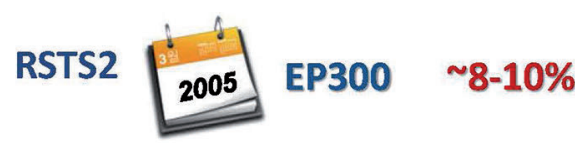

E1A-Binding Protein 300

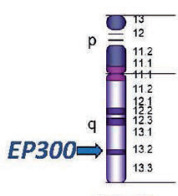

CHR 22

Fig. 5. I geni della Sindrome di Rubinstein-Taybi: CREBBP ed EP300: localizzazione cromosomica e percentuali di pazienti con diagnosi clinica giustificate dalle loro mutazioni. 


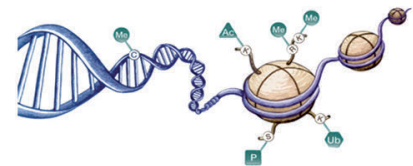

\section{CBP \& p300 (КАTЗA) (КАTЗB)}
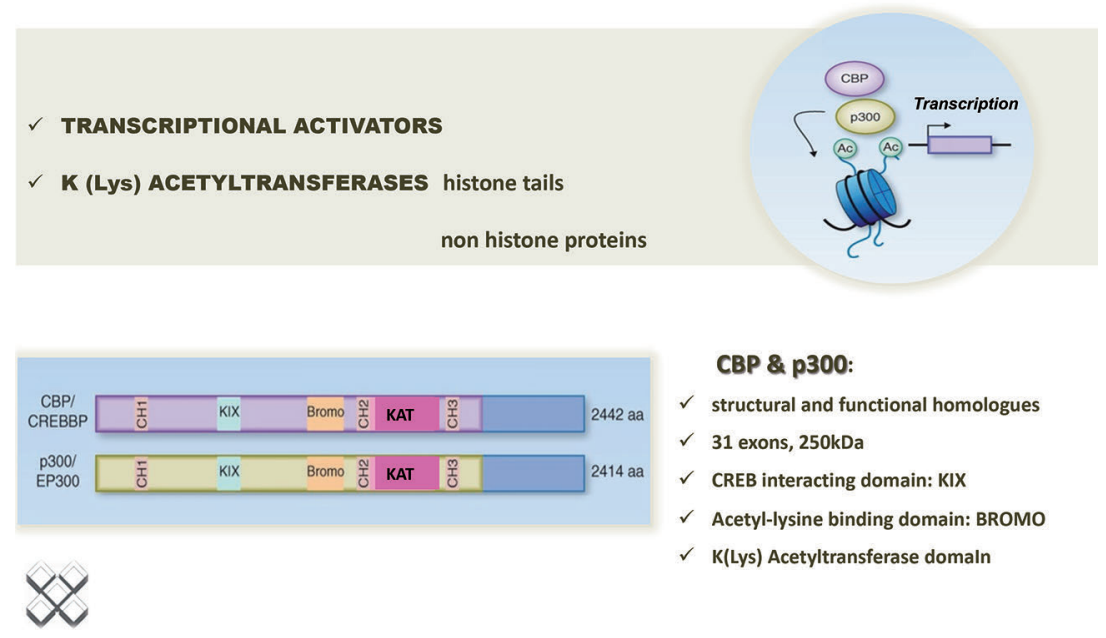

\section{CBP \& p300:}

$\checkmark$ structural and functional homologues

$\checkmark 31$ exons, $250 \mathrm{kDa}$

$\checkmark$ CREB interacting domain: KIX

$\checkmark$ Acetyl-lysine binding domain: BROMO

$\checkmark$ K(Lys) Acetyltransferase domaln

Fig. 6. Le proteine CBP e p300: coattivatori della trascrizione genica con attività acetiltrasferasica diretta verso la lisina $(K)$ sia delle code degli istoni della cromatina che di proteine non istoniche. Lo schema della loro struttura con i vari domini (al centro il dominio KAT) evidenzia l'omologia di sequenza e rende conto delle funzioni condivise. Rilevante il ruolo nello sviluppo del sistema nervoso e nella plasticità neurale. 


\section{CBP/p300 Mediators of several signaling pathways}

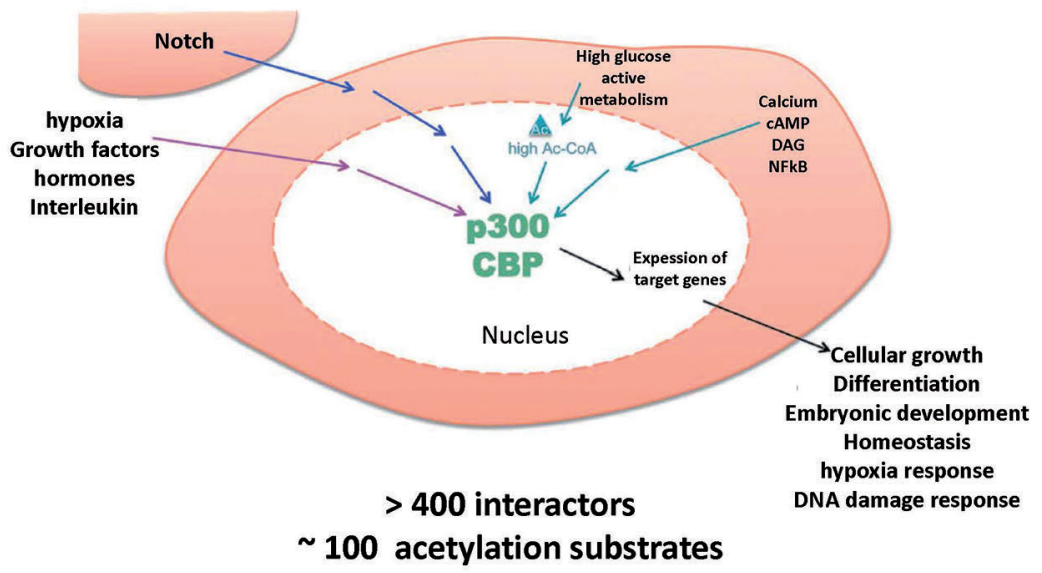

Fig. 7. Le proteine nucleari CBP e p300: mediatori di un numero elevatissimo di pathways di signaling extra-, inter-e intracellulari grazie alla loro capacità di legare una moltitudine di proteine diverse (ad oggi riconosciuti $>400$ interattori) usando $i$ loro domini di interazione fungendo anche da "scaffold" tra interattori diversi. 


\section{GENETIC \& EPIGENETIC INFORMATION}
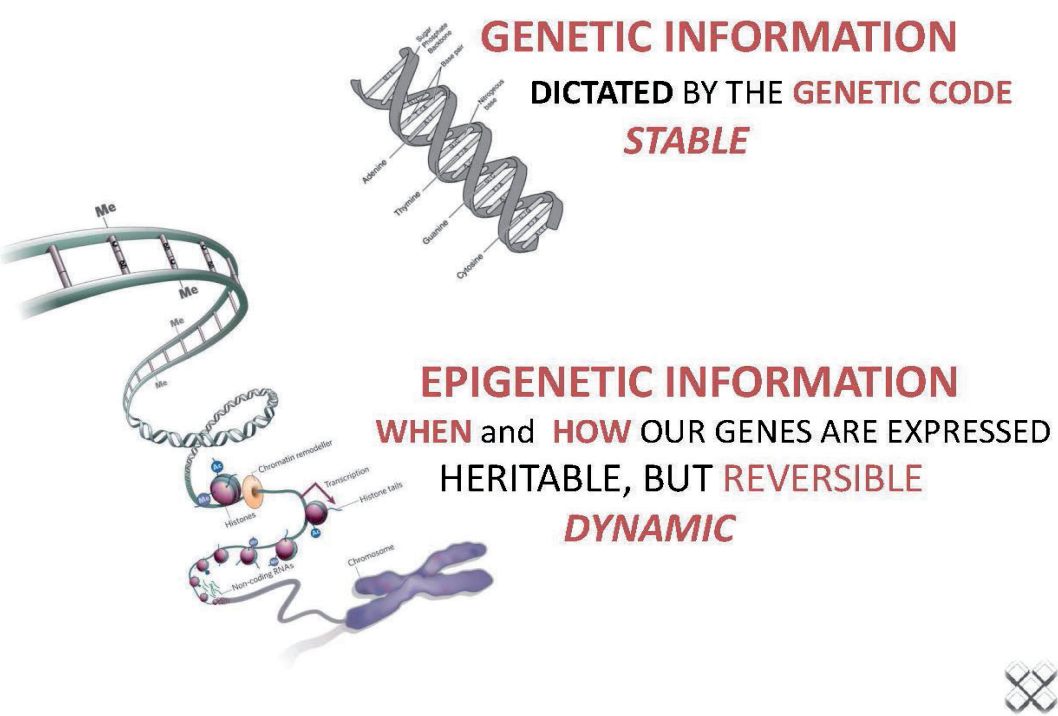

Fig. 8. Informazione Genetica ed Epigenetica. La prima è dettata dalla sequenza delle basi del DNA, è stabile e irreversibile, mentre l'informazione epigenetica, rappresentata da metilazione di una delle 4 basi del DNA (citosina) e da modificazioni post-traduzionali degli istoni della cromatina, è ereditabile, ma dinamica e reversibile. Le modificazioni epigenetiche controllano quando $e$ come $i$ nostri geni sono espressi. 


\section{KEY CHROMATIN MODIFICATIONS CONTRIBUTING TO THE EPIGENOME FUNCTION}

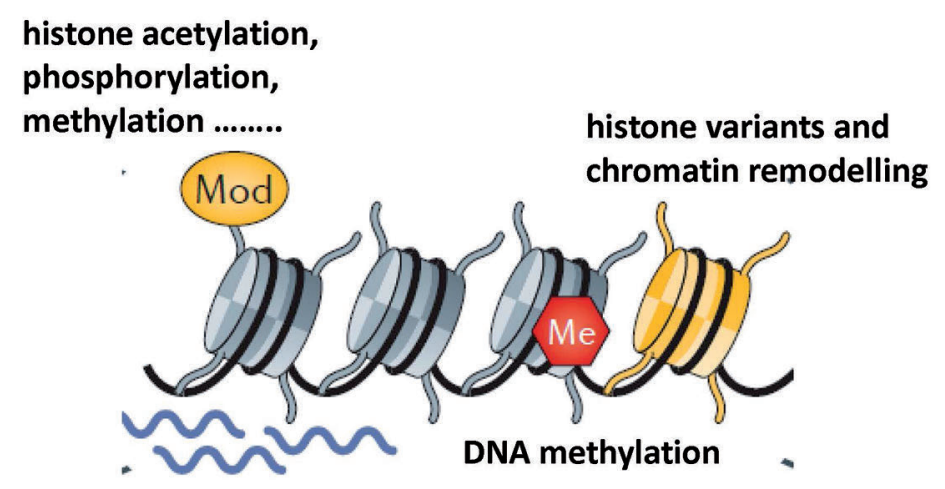

non coding RNA (ncRNA)

Fig. 9. Principali modificazioni epigenetiche: metilazione del DNA, modificazioni degli istoni, varianti istoniche e piccoli RNA non codificanti. Tali modificazioni definiscono la struttura tridimensionale della cromatina (il DNA complessato a proteine istoniche nel nucleo delle cellule eucariotiche) fungendo da ponte molecolare tra il controllo della trascrizione genica e l'ambiente. 


\section{PLAYERS OF EPIGENETIC MACHINERY}

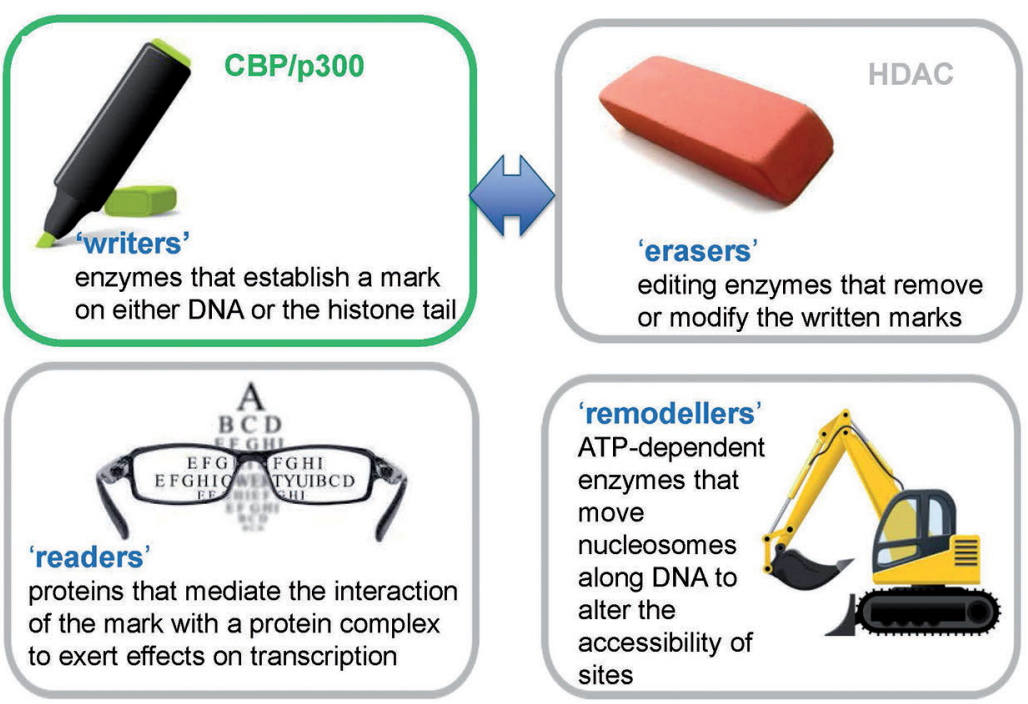

Fig. 10. I principali players dell'apparato epigenetico: "writers", "erasers", "readers" e "remodellers". E' evidenziata l'azione enzimatica opposta di writers ed erasers, qui esemplificata per CBP/p300 e istondeacetilasi (HDAC): in condizioni normali esiste una bilancia precisa tra queste attività enzimatiche, mentre a seguito di un difetto di CBP o p300, l'equilibrio si sposta a favore delle HDAC. 


\section{MENDELIAN DISORDERS OF THE EPIGENETIC MACHINERY}

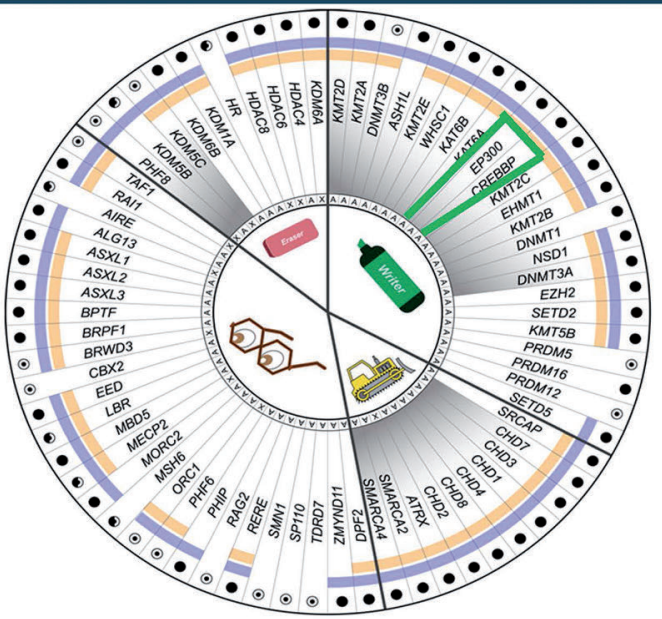

Fahrner \& Bjornsson 2019

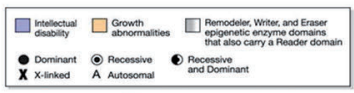

Fig. 11. Disordini mendeliani dell'apparato epigenetico, causati da mutazioni in geni che codificano proteine con domini "epigenetici" classificati nelle categorie di "writers", "erasers", "readers" e "remodellers" (icone al centro). I domini enzimatici (writer, eraser, remodeller) sono mutualmente esclusivi in ogni data proteina, ma molti coesistono con un dominio reader (sfumatura grigia). La maggior parte dei geni causa la patologia in condizione eterozigote (circolo pieno). La disabilità intellettiva è condivisa dalla maggior parte di questi disordini (cerchio viola) cosi come i difetti della crescita (cerchio arancione). La sindrome di Rubinstein-Taybi (1 e 2) (riquadro verde) risulta da mutazioni nei geni CREBBP o EP300 codificanti per proteine con attività acetiltransferasica (writers) provviste anche di un dominio "reader". (Ristampato con permesso. Human Molecular Genetics, Volume 28, Issue R2, 15 October 2019, Pages R254-R264, https://doi.org/10.1093/ hmg/ddz174). 


\section{iPSC NEURAL MODEL FOR RSTS}

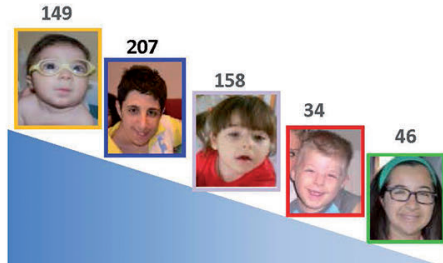

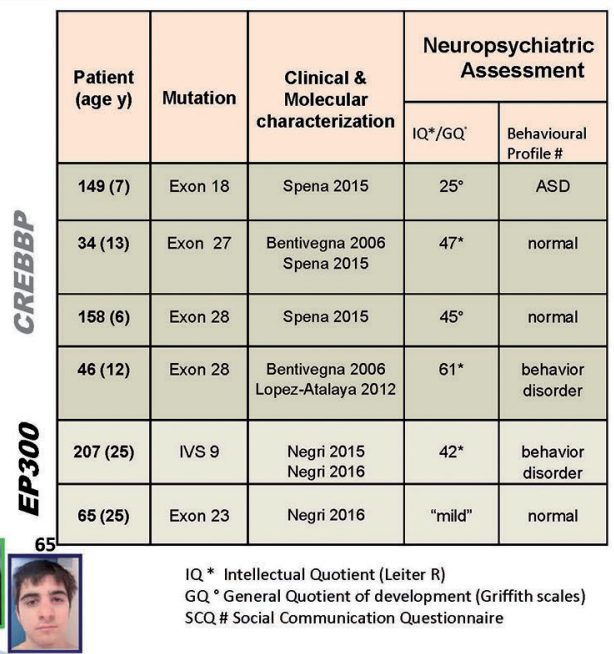

Cognitive impairment

Fig. 12. Modello di neuroni iPSC-derivati per la sindrome di Rubinstein-Taybi: la riprogrammazione a iPSC e il differenziamento a neuroni corticali è stato effettuato per 6 pazienti RSTS, 4 CREBBP-e 2 EP300-mutati qui ordinati secondo il livello di deficit cognitivo dal più grave al più lieve. Sono riportati l'età di ciascun paziente al momento della riprogrammazione, e la valutazione neuropsichiatrica. 


\section{WORKFLOW}
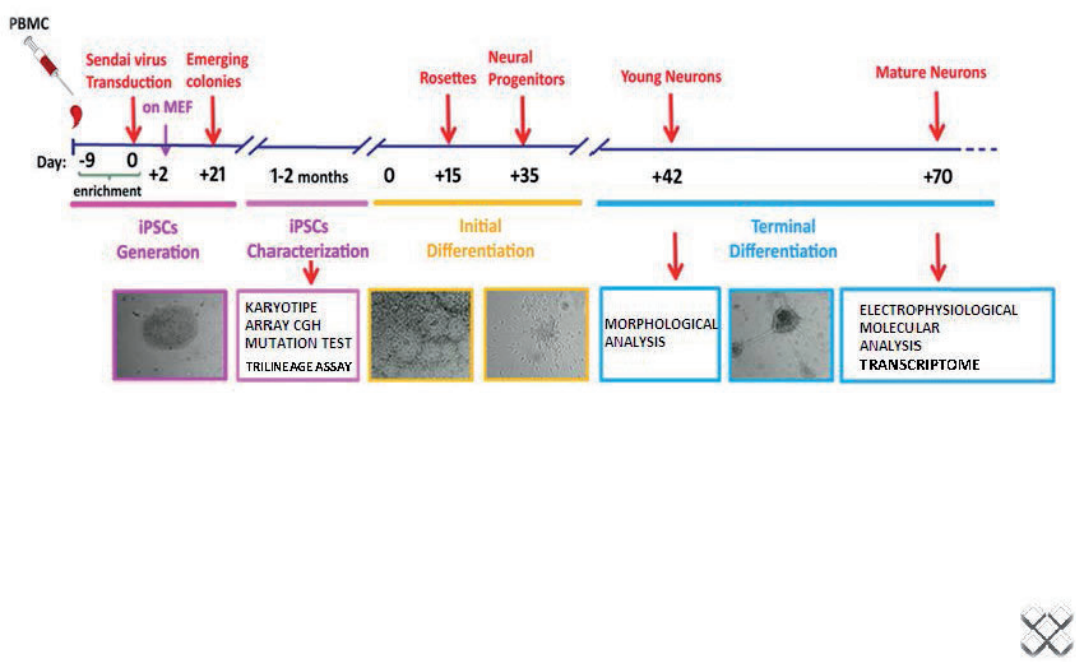

Fig. 13. Generazione di neuroni iPSC-derivati da pazienti RSTS e individui sani: workflow. Vedi testo per dettagli. 


\section{CHARACTERIZATION OF 3 CREBBP-MUTATED IPSC LINES: IF , FACS ANALYSIS AND TRILINEAGE DIFFERENTIATION POTENTIA L}
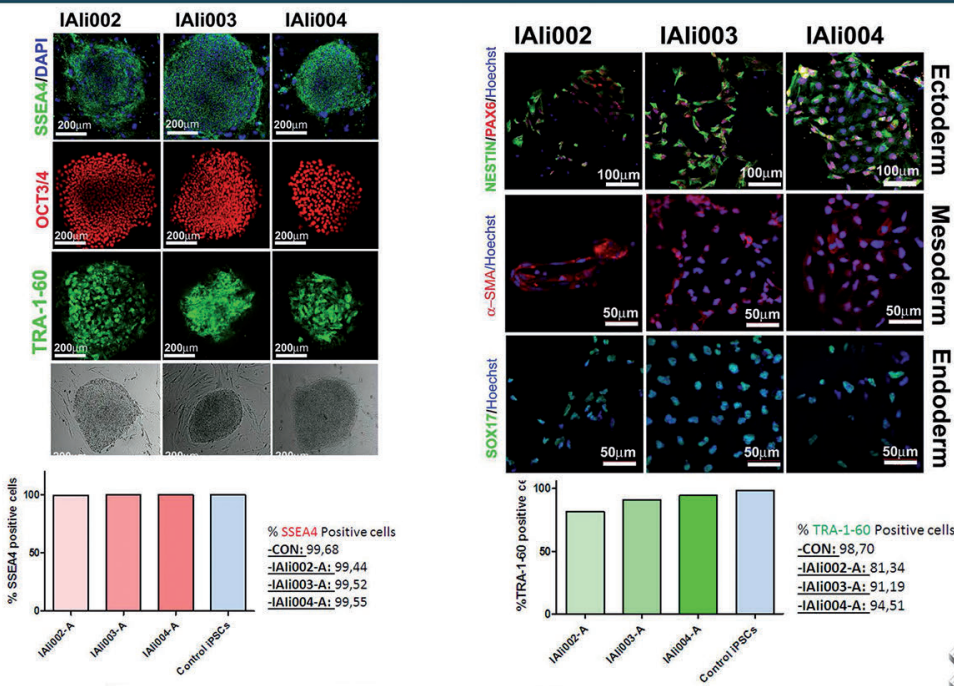

Fig. 14. Caratterizzazione di tre linee iPSC generate da pazienti CREBBP-mutati. Pannello a sinistra: espressione positiva degli antigeni di staminalità (SSEA4, OCT3/4 e TRA-1-60) valutata qualitativamente in immunofluorescenza al microscopio confocale, e quantitativamente al FACs (SSEA4 e TRA-1-60) e morfologia distintiva delle colonie al microscopio rovesciato. Pannello a destra: potenziale differenziativo delle colonie iPSC lungo l'asse ectodermico (Tra-1-60 +), mesodermico (alfa-SMA+) e endodermico (SOX17+). 


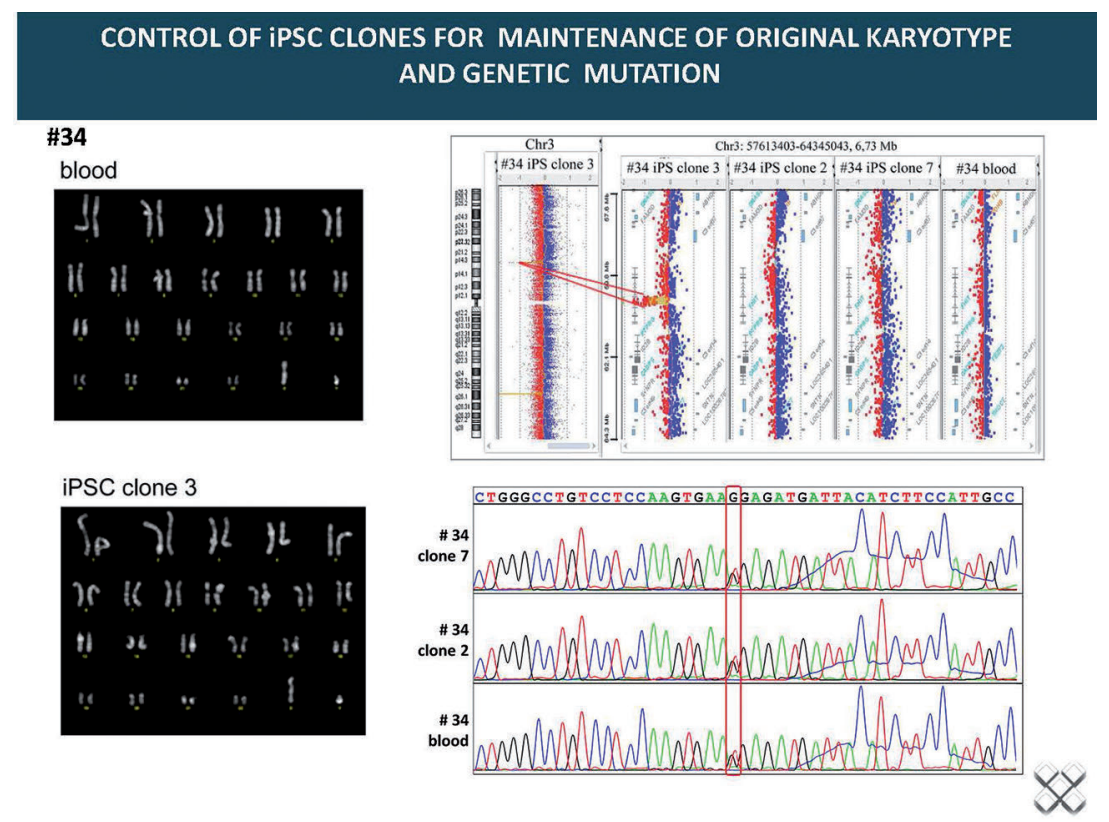

Fig. 15. Caratterizzazione della stabilità genomica di tre cloni iPSC di un paziente CREBBP-mutato. Pannello a sinistra: cariotipo in bande $Q$ dei linfociti del sangue periferico del paziente 34 (in alto) e del clone 3 delle iPSC generate dallo stesso paziente, che non mostra apparenti anomalie (in basso). Pannello a destra: in alto profilo del cromosoma 3 mediante ibridazione genomica comparativa su array (array-CGH) che mostra nel clone iPSC 3 del paziente una rara delezione in corrispondenza della regione 3p14.2 (indicata dalle linee rosse convergenti). Questa variante non è presente nei cloni iPSC 1 e 7 e nel sangue periferico del paziente ed è presumibilmente insorta in vitro: il clone iPSC 3 viene pertanto scartato. In basso: il sequenziamento Sanger del DNA genomico dal sangue periferico e $i$ cloni iPSC 7 e 2 del paziente evidenzia la mutazione in eterozigosi c.4435G>T nell'esone 27 del gene CREBBP (riquadro rettangolo rosso). 


\section{Selected clones are differentiated in cortical neurons, according} to monolayer protocol.

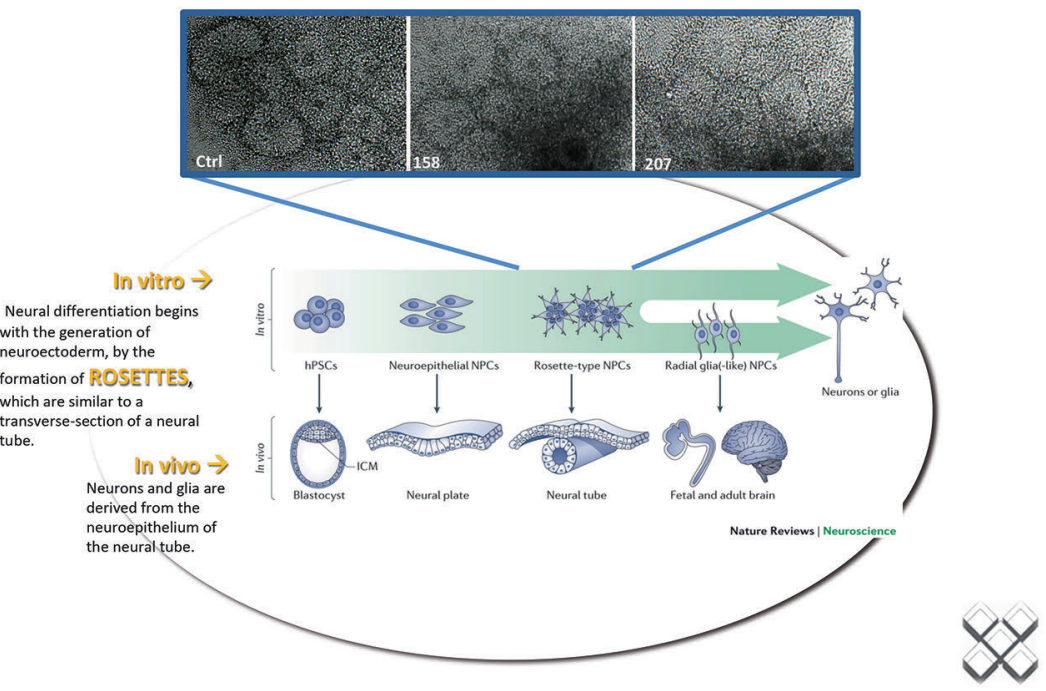

Fig. 16. Differenziamento neurale in vitro $e$ in vivo. A due settimane dall' inizio del differenziamento neurale secondo il protocollo in monostrato compaiono le rosette mostrate al microscopio a contrasto di fase per un controllo e due pazienti RSTS. Si noti la loro somiglianza alla sezione trasversale del tubo neurale che si origina in vivo dalla piastra neurale. 


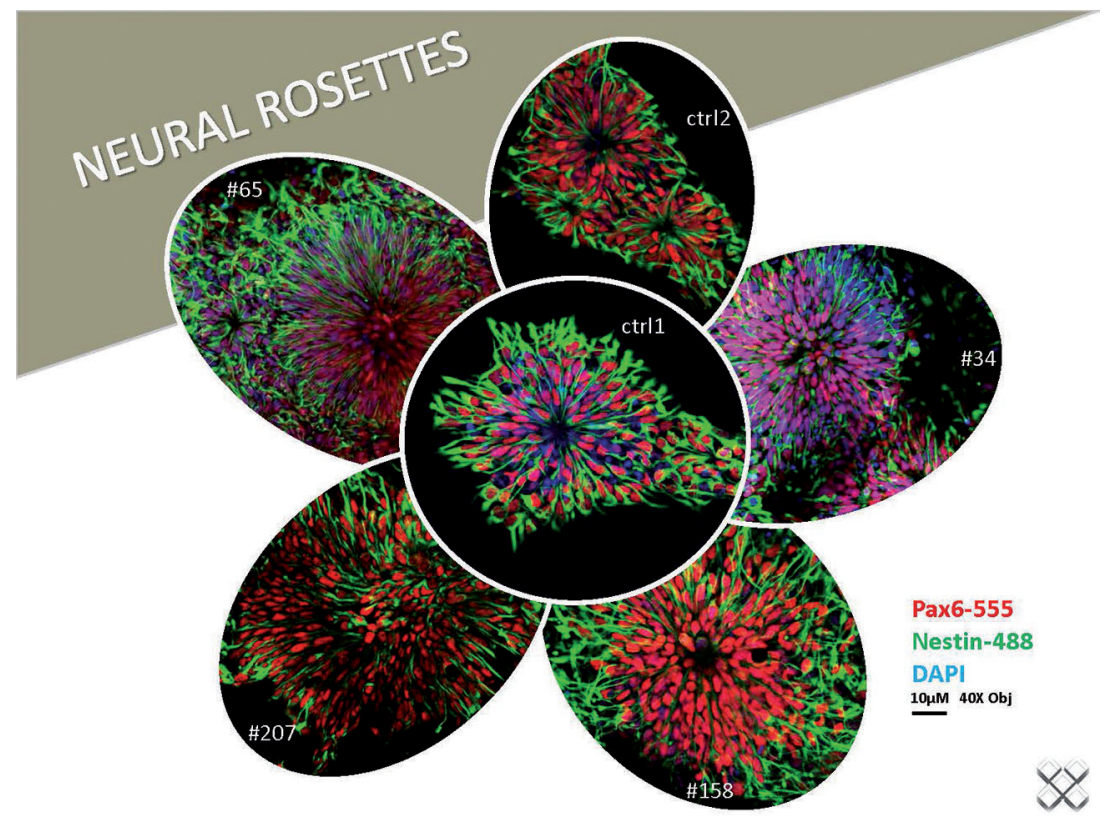

Fig. 17. Caratterizzazione mediante immunofluorescenza di rosette (20 giorni) di controlli e pazienti RSTS. Positività per $i$ marcatori neuroectodermici Nestina e PAXG. Controcolorazione dei nuclei con DAPI. 


\section{2 days NEURONS}

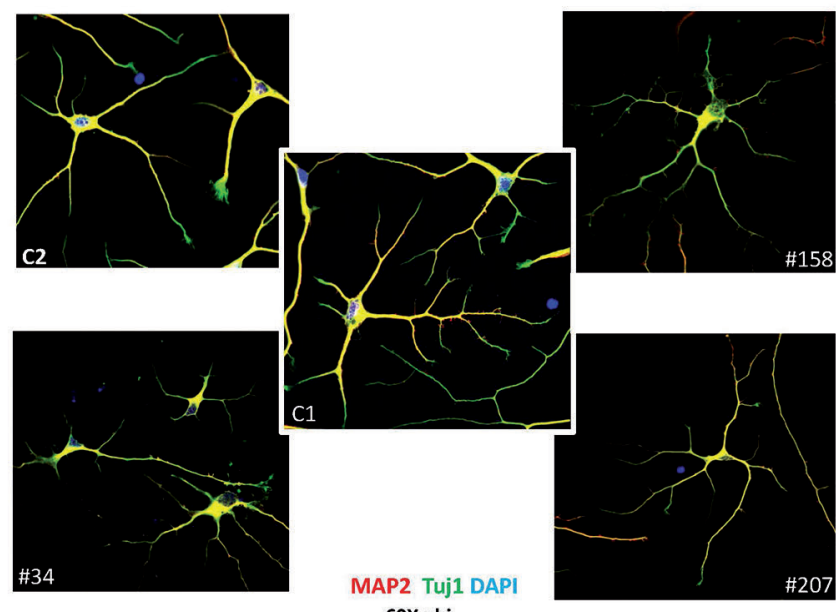

$60 \mathrm{X}$ obj

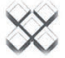

Fig. 18. Caratterizzazione mediante immunofluorescenza di neuroni a 42 giorni di controlli e pazienti RSTS. Positività per i marcatori pan neuronali MAP2 (Microtubule-associated protein 2) e TUJ1 (Tubulina betaIII). Controcolorazione dei nuclei con DAPI. 

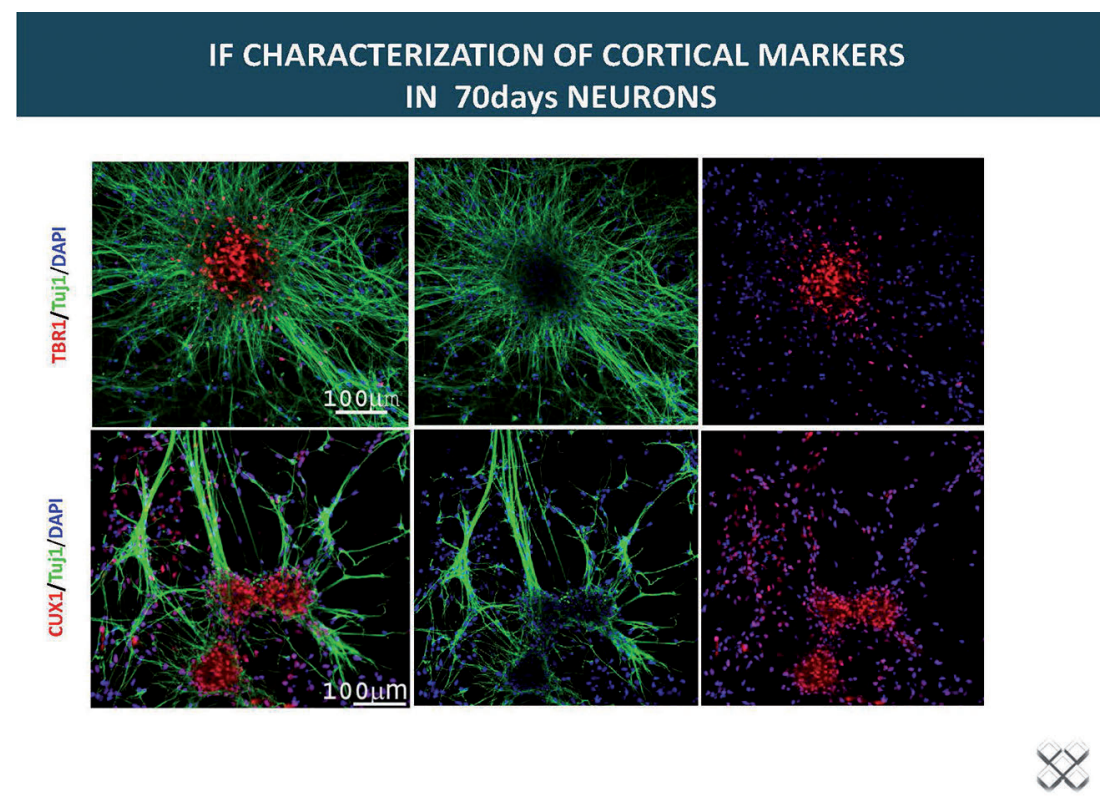

Fig. 19. Immunofluorescenza di neuroni postmitotici (>70 giorni). Positività per TUJ1 e i marcatori corticali TBR1 e CUX1. 


\section{POSITIVE IMMUNOSTAINING OF SYNAPTOPHISYN IN 70 DAYS NEURONS} SYP/TUJ1/ DAPI

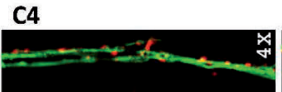

\#34

\#46
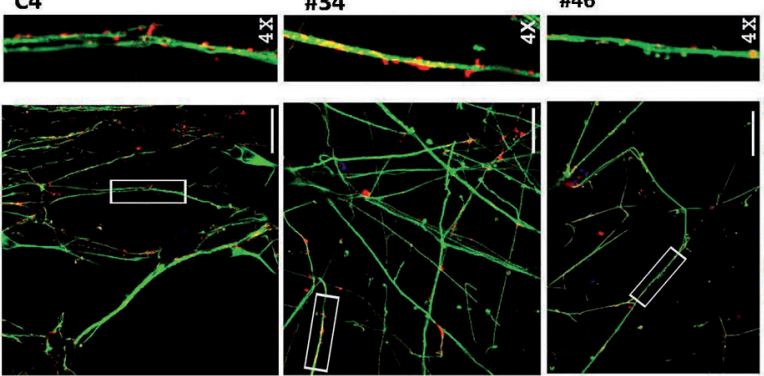

\#65
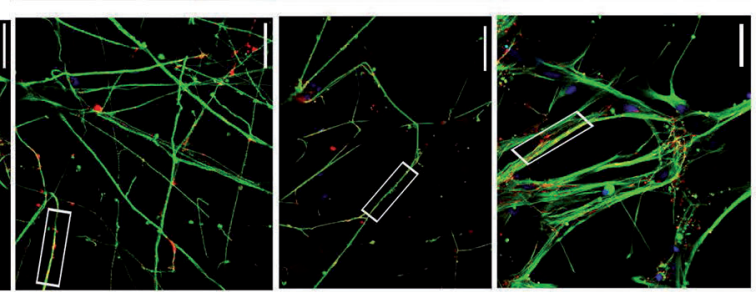

Fig. 20. Immunofluorescenza di neuroni (>70 giorni) di un controllo e 3 pazienti RSTS. Positività per TUJ1 e il marcatore pre-sinaptico sinaptofisina (SYP). I campi incorniciati sono mostrati a ingrandimento $4 x$ sopra le rispettive foto. 


\section{CHARACTERIZATION OF EXCITATORY AND INHIBITORY MARKERS IN} 70-DAYS NEURONS

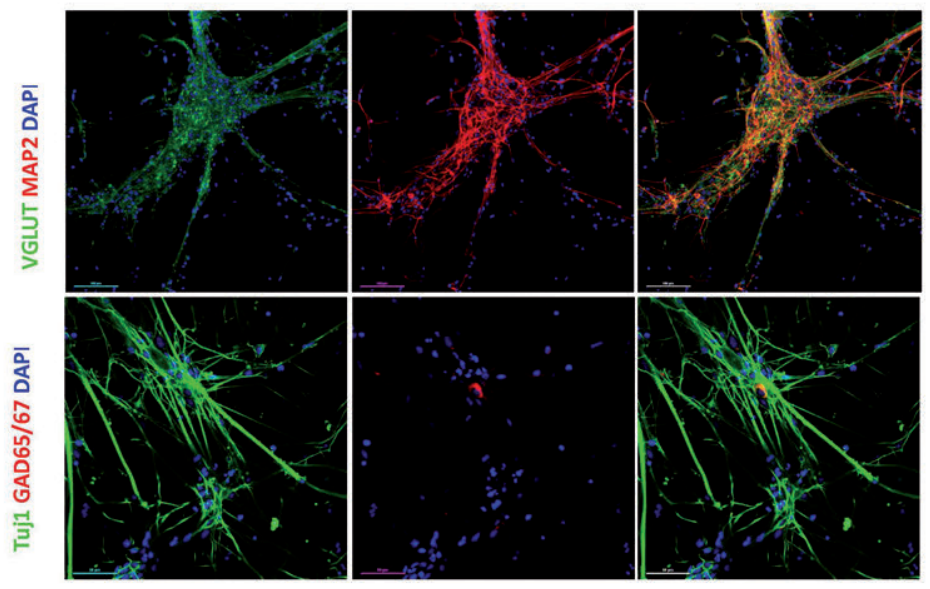

Fig. 21. Immunofluorescenza di neuroni postmitotici (>70 giorni) per vGLUT1/2, marker dei neuroni eccitatori e MAP2 e per GAD65/67, marker dei neuroni inibitori e TUJ1. Sia nei neuroni di controllo che in quelli dei pazienti RSTS i neuroni positivi pervGLUT 1/2, concentrati nei nodi ad alta densità cellulare sono molto più numerosi dei neuroni positivi per i marker inibitori. 


\section{MORPHOLOGICAL ANALYSIS}
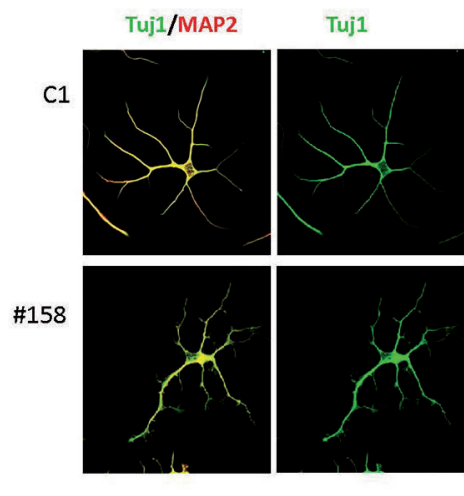

Binary

Skeleton
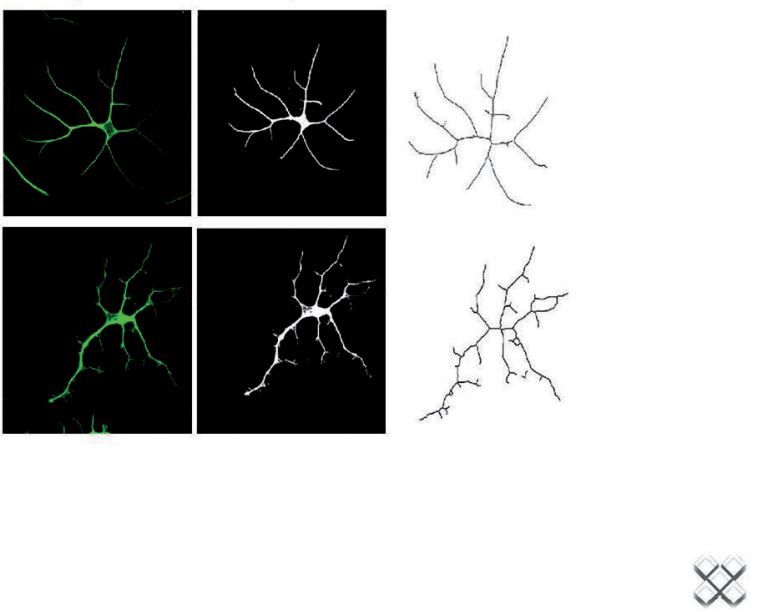

Fig. 22. Analisi morfologica dei neuroni a 42 giorni. Parametri morfologici, quali la lunghezza e il numero dei "branches" sono analizzati in neuroni giovani, presenti nelle piastre a bassa densità, utilizzando la Plugin "Analyze skeleton" (Image J). Come mostrato per neuroni di un controllo e di un paziente RSTS la stessa cellula singola la cui identità neuronale è confermata dalla positività per MAP2 e TUJ1 è elaborata come immagine binaria e ridotta a "sketeton" in modo da permettere di contare precisamente la lunghezza delle ramificazioni (branches) e il loro numero. L'analisi di un numero medio di 30-50 cellule di 3 campioni di controllo e 5 di pazienti RSTS ha permesso di graficare questi parametri. 


\section{STATISTICAL ANALYSES OF MORPHOLOGICAL FEATURES ACQUIRED BY 42 DAYS} NEURONS OF PATIENT-SPECIFIC IPSC

A)

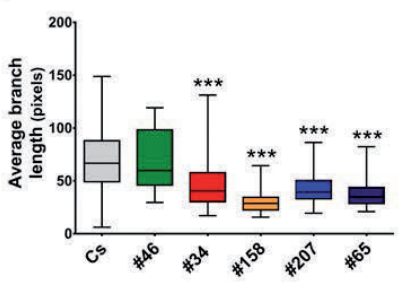

C)

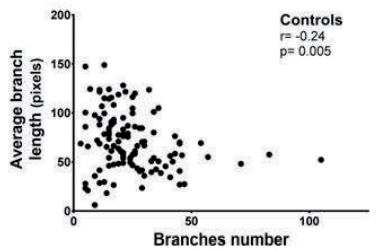

B)

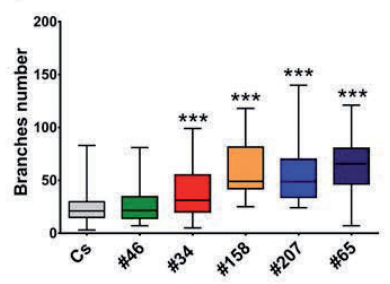

D)

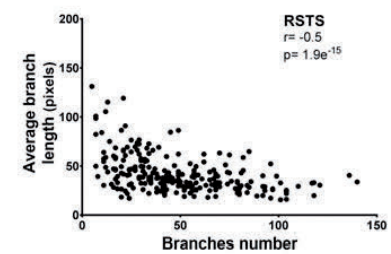

Fig. 23. Analisi statistica di parametri morfologici ottenuti analizzando neuroni di 42 giorni ottenuti da iPSC di 5 pazienti RSTS. A) I box plots mostrano che i neuroni dei pazienti RSTS con l'eccezione di P46 hanno una lunghezza media dei branches significativamente ridotta rispetto a quella di un pool di neuroni di controllo. B) i box plots evidenziano un distribuzione simile ma opposta per il numero medio dei branches con i neuroni di P46 simili ai controlli e quelli degli altri pazienti con numero medio di branches significativamente maggiore dei controlli. La tendenza opposta di questi due parametri morfologici nei pazienti RSTS è confermata dall'analisi di correlazione $(C, D)$ : la lunghezza e il numero medio dei branches sono negativamente correlati nei pazienti, mentre la correlazione è debole nei controlli. 


\section{E-RECORDINGS}
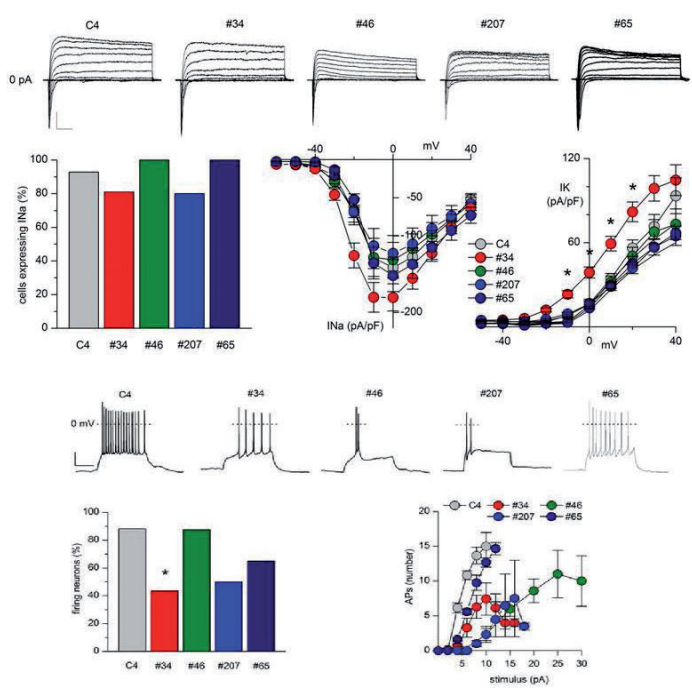

Fig. 24. Caratterizzazione elettrofisiologica di neuroni di controllo e di pazienti RSTS dopo $>70$ giorni di differenziamento. Pannelli superiori: Come si evidenzia dalle tracce rappresentative delle correnti ioniche totali indotte da stimoli depolarizzanti i neuroni di pazienti RSTS si comportano in modo simile a neuroni maturi: le correnti di sodio sono di ampiezza paragonabile, quelle di potassio hanno un'ampiezza accresciuta rispetto a neuroni del controllo solo in P34. Pannelli inferiori: rispetto a neuroni di controllo una ridotta percentuale di neuroni di P34 e P207 é in grado di generare potenziali d'azione ; inoltre i neuroni di tutti i pazienti investigati si dimostrano meno eccitabili, come dimostrato dai rapporti "input-output", richiedendo uno stimolo di intensità superiore per raggiungere la soglia necessaria per generare potenziali d'azione. 
Stem Cell Research 30 (2018) 130-140

iPSC-derived neurons of CREBBP- and EP300-mutated Rubinstein-Taybi syndrome patients show morphological alterations and hypoexcitability

Valentina Alari $^{\mathrm{a}, 1}$, Silvia Russo ${ }^{\mathrm{a}, 1}$, Benedetta Terragni ${ }^{\mathrm{b}}$, Paola Francesca Ajmone ${ }^{\mathrm{c}}$,

Alessandra Sironi $^{\mathrm{a}}$, Ilaria Catusi ${ }^{\mathrm{a}}$, Luciano Calzari ${ }^{\mathrm{a}}$, Daniela Concolino ${ }^{\mathrm{d}}$, Rosa Marotta ${ }^{\mathrm{d}}$,

Donatella Milani ${ }^{\mathrm{e}}$, Daniela Giardino ${ }^{\mathrm{a}}$, Massimo Mantegazza ${ }^{\mathrm{b}, f, g}$, Cristina Gervasini ${ }^{\mathrm{h}}$,

Palma Finelli ${ }^{\mathrm{a}}$, Lidia Larizza ${ }^{\mathrm{a}, \mathrm{e}}$

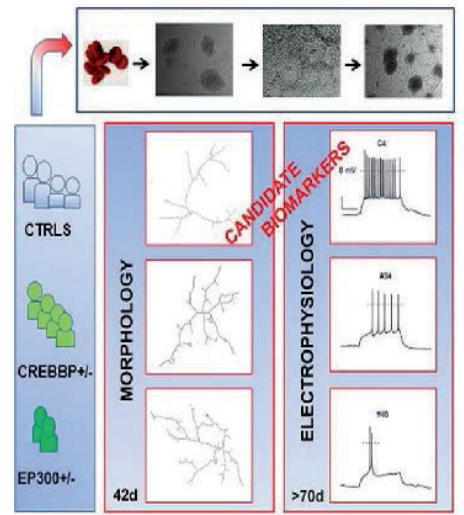

Highlights

- First established iPSC-derived neuronal model for RubinsteinTaybi syndrome(RSTS).

- Both CREBBP- and EP300-mutated patients modelled.

- RSTS early neurons show reduced average branch length and increased branch number.

- RSTS neurons are able to generate action potentials but are hypoexcitable.

Fig. 25. Conclusioni dello studio: Generazione del primo modello neuronale iPSC-derivato per la sindrome di Rubinstein-Taybi. I neuroni RSTS in differenziamento presentano ridotta lunghezza e aumentato numero dei "branches". I neuroni RSTS postmitotici sono in grado di generare potenziali d'azione, ma sono ipoeccitabili. 


\section{RSTS : THERAPEUTIC PERSPECTIVES ????}

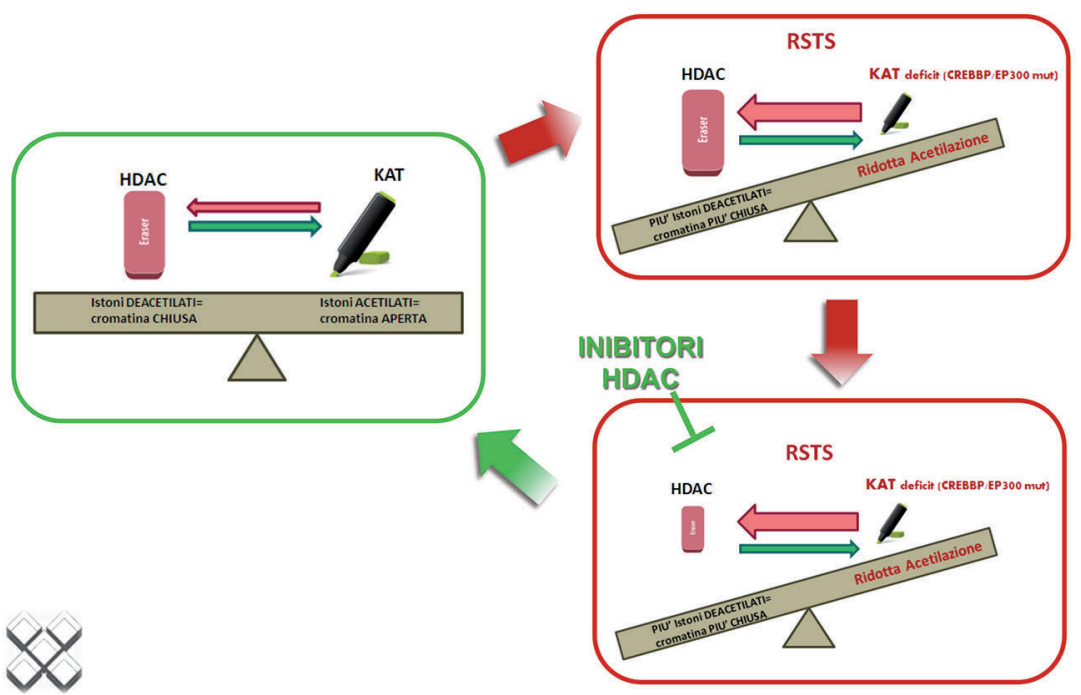

Fig. 26. Prospettive di terapia postnatale per i pazienti RSTS: il difetto di CBP o p300 determina un deficit di acetilazione di proteine istoniche e non istoniche che fa pendere la bilancia tra istonacetiltransferasi (KAT) e istondeacetilasi (HDAC) a favore di queste ultime. Inibitori delle HDAC (HDACi) posssono ripristinare l'equilibrio. 


\section{TSA PARTIALLY RESCUES THE NUCLEAR SIZE REDUCTION OF P149 NEURAL} PROGENITOR LINES

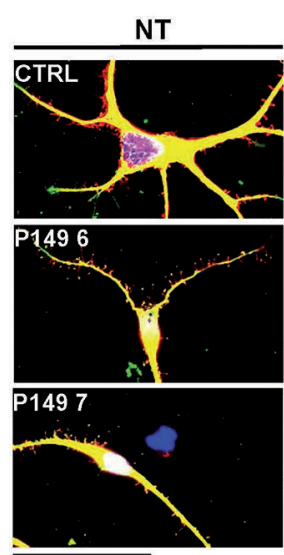

$50 \mu \mathrm{m}$

\section{+TSA 20nM}

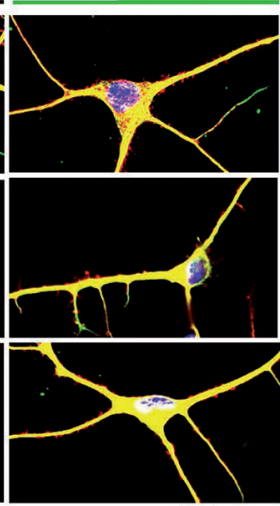

Obj.
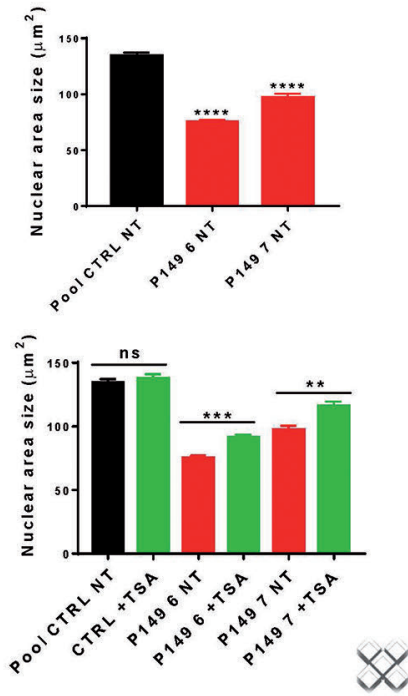

Fig. 27. Trattamento con Tricostatina A (TSA) e attenuazione di alterazioni morfologiche dei neuroni giovani del paziente 149, il più grave per il fenotipo neurocognitivo tra quelli modellati. TSA 20nM supplementata per una settimana al terreno di coltura di due linee indipendenti di progenitori neurali di P149 corregge la ridotta dimensione dell'area nucleare osservabile nelle linee non trattate. 
ELECTROPHYSIOLOGICAL CHARACTERIZATION OF NEURONS FROM CONTROL, PATIENT \#149 AND \#149 AFTER TRICHOSTATIN TREATMENT (\#149+TSA)

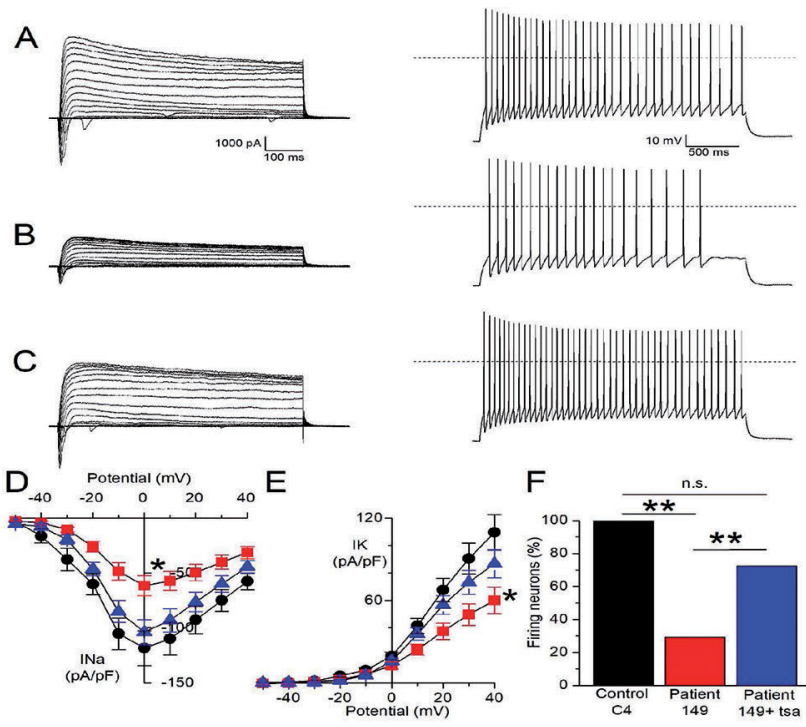

Fig. 28. Trattamento cronico con TSA e parziale reversione delle disfunzioni agli e-recordings di neuroni $>70$ giorni di P149. A, B, C: correnti ioniche totali dei neuroni di un controllo, di P149 e P149 dopo trattamento «long term» (35 giorni) con TSA (0.2 nM). D: plot della quantificazione della densità delle correnti di sodio a diversi potenziali per C4 (cerchietti neri, P149 (quadrati rossi) e P149 +TSA (triangoli bleu). E: plot della quantificazione delle densità delle correnti di potassio a diversi potenziali (simboli analoghi). F: quantificazione della percentuale di neuroni in grado di generare almeno un potenziale d'azione per C4, P 149 e P149 trattato con TSA. La differenza tra C4 e P149+TSA esiste, ma non è significativa, mentre lo è tra C4 e P149 e tra P149 e P149+TSA. 
